\title{
Initial Coin Offerings as Investment Contracts: Are Blockchain Utility Tokens Securities?
}

Nate Crosser*

\section{INTRODUCTION}

Current American jurisprudence on digital assets (e.g. Bitcoin) is woefully underdeveloped due to the rapid development and adoption of blockchain technology - creating an intellectual gold rush with agencies, attorneys, and techies all shouting their positions (on securities laws, particularly) into the wind. This Comment enters the ether in an endeavor to counter prevailing federal agency narratives about the role of securities laws regarding "ICOs"-introducing the reader to the most pertinent features of blockchain technology and Initial Coin Offerings, introducing the U.S. Securities and Exchange Commission's (the "SEC") current regulatory approach, and applying the seminal Howey is-it-a-security test.

Initial Coin Offerings (ICOs) are the online sale of cryptographic assets used to launch a cryptocurrency, finance a blockchain application development project, or sell access to features of a blockchain application. ${ }^{1}$ ICOs, also called Token Sales or Token Generation Events, are financing mechanisms popularly viewed as a hybrid of a Wall Street Initial Public Offering of Stock (IPO), ${ }^{2}$ venture capital, ${ }^{3}$ and crowdfunding (like Kickstarter). ${ }^{4}$ ICOs can be used to facilitate a broad range of

*J.D. 2019, University of Kansas School of Law. I would like to thank the Kansas Law Review editorial staff for their diligence and patience, Professor Webb Hecker for his input, and the inventor of espresso.

1. What is an ICO?, BITCOIN MAGAZINE (last visited Oct. 9, 2018) https://bitcoinmagazine.com/guides/what-ico/ [https://perma.cc/S37R-WKVH].

2. Kalyeena Makortoff, UK Launches 'Deeper Examination' of ICO Cryptocurrency Tokens After Consumer Warning, INDEPENDENT.IE (Dec. 15, 2017, 2:16 PM), https://www.independent.ie/ world-news/uk-launches-deeper-examination-of-ico-cryptocurrency-tokens-after-consumer-warning36411753.html [https://perma.cc/5SDU-YQ3J].

3. Annie Palmer, Venture Capitalists Warming Up to Cryptocurrency Initial Coin Offerings, THESTREET (Dec. 19, 2017, 4:48 PM), https://www.thestreet.com/story/14424493/1/venturecapitalists-warm-up-to-initial-coin-offerings.html [https://perma.cc/2VUZ-XQB2].

4. James Titcomb, US Regulator Warns of 'Fraud and Manipulation' Amid Cryptocurrency Craze, TelegraPh, (Dec. 12, 2017, 5:43 PM), https://www.telegraph.co.uk/technology/ 2017/12/12/us-regulator-warns-fraud-manipulation-amid-cryptocurrency-craze/ [https://perma.cc/ 7XTE-GC9Y]. 
offerings with varying features and varying legitimacy, but they generally use the same underlying blockchain technology and all follow a similar process: promoters write a white paper detailing a proposed or existing decentralized blockchain application (or "DAPP") 5 and solicit the exchange of existing cryptocurrencies (like Bitcoin or Ether) or fiat currencies (like US Dollars) for units of a the new internal digital currency (tokens or coins). ${ }^{6}$

Blockchain applications have massive economy-disrupting potential. Some proponents compare them to the advent of the Internet itself and they are certainly one of the largest hotbeds of innovation and investment of the early 21 st century. ${ }^{7}$ As of mid-December 2017, ICOs had raised nearly $\$ 4$ billion $^{8}$ globally to fund or launch DAPPs, with pre-product startups and tech giants alike capitalizing on the catalytic process. Like other developments of the so-called Fourth Industrial Revolution, like the "Internet of Things" (IOT), virtual reality, robotics, artificial intelligence, and synthetic biology, DAPPs and their enabling-ICOs provide the opportunity for unprecedented innovation ${ }^{9}$ and a commensurate redistribution of wealth — creating a gold-rush mentality ${ }^{10}$ as early adopters hope to cash in. The ICO model has massive potential for promoting innovation and the democratization of entrepreneurial

5. Alyssa Hertig, What is a Decentralized Application?, COINDESK, https://www.coindesk.com/information/what-is-a-decentralized-application-dapp/ [https://perma.cc/ 335M-66BF] (last visited Oct. 24, 2018).

6. Chance Barnett, Inside the Meteoric Rise of ICOs, ForBES (Sept. 23, 2017, 1:21 AM), https://www.forbes.com/sites/chancebarnett/2017/09/23/inside-the-meteoric-rise-oficos/\#10945aff5670 [https://perma.cc/8NQC-RMSV].

7. Randolph A. Robinson II, The New Digital Wild West: Regulating the Explosion of Initial Coin Offerings, 9-11 (Dec. 14, 2017, last revised Aug. 16, 2018) (unpublished manuscript) (on file with the Tennessee Law Review).

8. Steven Russolillo, Initial Coin Offerings Surge Past \$4 Billion-And Regulators Are Worried, WALL ST. J. (Dec. 14, 2017, 4:54 AM), https://www.wsj.com/articles/initial-coin-offeringssurge-past-4-billionand-regulators-are-worried-1513235196 [https://perma.cc/9T79-CNGG].

9. Nick Ismail, Blockchain: Funding the Fourth Industrial Revolution?, INFORMATION AGE (Nov. 6, 2017), http://www.information-age.com/blockchain-funding-fourth-industrial-revolution123469365/ [https://perma.cc/SUD2-2J3J].

10. Claire Brownell, Perils of the Crypto Currency Gold Rush, NAT'L Post (Canada), (Nov. 22, 2017), https://www.pressreader.com/canada/national-post-latest-edition/20171122/28182716906 9805 ("Investors are not doing their due diligence.... There's greed in the market." (citations omitted)). Some issuers have made light of this market hysteria by releasing tokens such as "Jesus Coin," "PonzICO," and "Useless Ethereum Token" - and actually raised real money. Id. 
finance, ${ }^{11}$ but critics voice valid concerns of market bubbles, ${ }^{12}$ cybersecurity threats, ${ }^{13}$ perverse incentives, ${ }^{14}$ hacking, ${ }^{15}$ money laundering, ${ }^{16}$ tax evasion, ${ }^{17}$ and fraud. ${ }^{18}$

As ICOs have become socially and economically vogue, they present novel regulatory challenges ${ }^{19}$ to governments across the world scrambling to keep pace with the industry. ${ }^{20}$ The ICO market has been called the "Wild West" of finance because the regulatory and technological

11. See, e.g., Robinson, supra note 7, at 10, 16-17; Lindsay Lin, 3 Common Misconceptions About ICO Law, Stellar (Aug. 31, 2017) [hereinafter 3 Common Misconceptions] https://www.stellar.org/blog/3-common-misconceptions-about-ICO-law/ [https://perma.cc/8LMSC2RL]; Laura Shin, Are ICOs For Utility Tokens Selling Securities? Prominent Crypto Players Say Yes, FORBES (Oct. 2, 2017, 9:15 AM), https://www.forbes.com/sites/laurashin/2017/10/02/are-icosfor-utility-tokens-selling-securities-prominent-crypto-players-say-yes/\#76c1e 7d934fa [https://perma.cc/BW2D-PUU9].

12. Anthony Coggine, Mark Cuban Considers Bitcoin a Bubble, Bitcoin Price Tumbles Again, COINTELEGRAH (June 8，2017), https://cointelegraph.com/news/mark-cuban-considers-bitcoin-abubble-bitcoin-price-tumbles-again [https://perma.cc/4PM9-G3AV]; Palmer, supra note 3.

13. DAO, Exchange Act Release No. 81207, at 1 (July 25, 2017) [hereinafter SEC Release], https://www.sec.gov/litigation/investreport/34-81207.pdf [https://perma.cc/B7U2-MXS8] (hackers were able to exploit slock.it's source code and steal close to one third of the ICO tokens, worth millions of dollars). Discussion of the implications of hacks such as these is beyond the scope of this note.

14. The paradigmatic ICO raises funds in the pre-product stage to develop a blockchain-enabled project, as opposed to more traditional private finance where funds are raised to scale an existing business after at least a prototype is created. This front-loading of investment potentially creates a financial incentive for organizations to create a "white paper" (a kind of informal prospectus) and raise funds through the ICO, then "take the money and run" to their next opportunity rather than exert full effort of developing the product. This incentive structure is why crowdfunding platforms like Kickstarter require prototypes and have protocols for returning funds to contributors. To combat this incentive structure, it is common practice for ICOs to have a depository agent who holds the funds frozen until the terms in the white paper are fulfilled. See Jin Enyi \& Ngoc Dang Yen Le, Regulating Initial Coin Offerings (“Crypto-Crowdfunding”), 8 J. INT’L BANKING \& FiN. L. (UK) 495 (Sept. 1, 2017).

15. See, e.g., Alex Hern, Bitcoin Buyer Beware: US SEC Warns 'Extreme Caution' Over Cryptocurrency Investments, GUARDIAN (Dec. 12, 2017, 6:25 AM), https://www.theguardian.com/ technology/2017/dec/12/bitcoin-buyer-beware-us-sec-warns-extreme-caution-over-cryptocurrencyinvestments [https://perma.cc/A64H-MAA2].

16. Francine McKenna, Here's How the U.S. and the World Regulate Bitcoin and Other Cryptocurrencies, MARKETWATCH (Dec. 28, 2017, 11:19 AM), https:/www.marketwatch.com/ story/heres-how-the-us-and-the-world-are-regulating-bitcoin-and-cryptocurrency-2017-12-18 [https://perma.cc/5EXJ-JF8V].

17. $I d$.

18. See Investor Alert: Bitcoin and Other Virtual Currency-Related Investments, U.S. SEC. \& EXCH. COMM'N (May 7, 2014), https://www.sec.gov/oiea/investor-alerts-bulletins/investoralertsia bitcoin.html [https://perma.cc/BKS7-BHST]; Wolfie Zhao, \$600 Fraud? Fake ICO White Papers Are Drawing Scrutiny, COINDESK (Updated Feb. 14, 2018, 7:07 UTC),

https://www.coindesk.com/600-fraud-fake-ico-white-papers-draw-scrutiny-in-china/ [https://perma.cc/AQQ4-XDQ5].

19. See Robinson, supra note 7, at 24-26.

20. McKenna, supra note 16. 
uncertainty at this bustling frontier of finance, technology, and the law. ${ }^{21}$

Among other agencies, the SEC, which regulates the sale of securities within its jurisdiction, has set its sights on ICOs because of similarities between ICOs and the sale of stocks and other investment vehicles, and to protect the American investing public against the financial mania ICOs have fueled. ${ }^{22}$ As of February 2018, many ICOs have been conducted, but none have been registered with the SEC despite the agency's clear intent to assert authority in the space. ${ }^{23}$ Since the popularization of ICOs in the late 2010s, the SEC has shut down multiple ICOs as the sale of unregistered securities. ${ }^{24}$ The SEC has done so pursuant to its regulatory prerogative set forth in the Securities Act of $1933 .{ }^{25}$

Although the SEC is clearly determined to regulate nearly all ${ }^{26}$ ICOs as the sale of securities, courts should exercise restraint and hold that ICOs of certain DAPP assets (i.e. true "utility tokens" as discussed later) can and sometimes should be viewed as the sale of digital consumer assets or commodities rather than investment contracts. In applying the seminal "investment contract" Howey test, courts can resist categorical

21. See generally Robinson, supra note 7; Jorge Pesok \& Samuel Brylski, SEC's Blockchain Stance Will Likely Impact Exchanges, LAw360 (Aug. 8, 2017, 2:10 PM), https://www.law360.com /articles/952055/sec-s-blockchain-stance-will-likely-impact-exchanges [https://perma.cc/ZC6YF333].

22. Barbara Shecter, 'It's Going Crazy': Canadian Watchdogs on High Alert over Initial Coin Offering 'Mania', FIN. Post (Dec. 18, 2017, 2:23 PM), https://business.financialpost.com/ technology/blockchain/its-going-crazy-canadian-regulators-on-alert-over-initial-coin-offering-mania [https://perma.cc/JJ4C-5JUP].

23. See, e.g., Joon Ian Wong, The US Senate Just Learned What Bitcoiners Mean by "Hodl", QUARTZ (Feb. 6, 2018), https://qz.com/1200204/bitcoin-regulation-cftc-and-sec-weigh-in-on-cryptooversight-at-us-senate-hearing/ [https://perma.cc/VC8S-CNFB]; Victor Reklaitis, SEC Chairman: Bitcoin Offers 'Substantially Less Investor Protection' than Other Markets, MARKETWATCH (Dec. 12, 2017, 7:35 AM), https://www.marketwatch.com/story/sec-chairman-bitcoin-offers-substantiallyless-investor-protection-than-other-markets-2017-12-12 [https://perma.cc/CS45-WCHY].

24. Graham Rapier, The SEC Has Shut Down Another ICO-This Time an Alleged \$600 Million Scam in Texas, BuS. INSIDER (January 30, 2018, 11:24 AM), https://markets.businessinsider.com /news/stocks/sec-shuts-down-arise-bank-600-million-alleged-ico-scam-dallas-texas-2018-11014571716 [https://perma.cc/LH3G-NM3N].

25. Daniel N. Budofsky \& Robert B. Robbins, The SEC's Shutdown of the Munchee ICO, PILlSBURY (Jan. 2, 2018), https://www.pillsburylaw.com/en/news-and-insights/the-secs-shutdownof-the-munchee-ico.html [https://perma.cc/EES5-ADEZ].

26. See William Hinman, SEC Director, Division of Corporate Finance, Digital Asset Transactions: When Howey Met Gary (Plastic) (June 14, 2018), https://www.sec.gov/news/speech /speech-hinman-061418 [https://perma.cc/9SUC-2QNR] (acknowledging the possibility of creating cryptographic assets that are digital consumer goods, and not securities); see also Jay Clayton, Chairman, SEC, Testimony on "Oversight of the U.S. Securities and Exchange Commission" Before the H. Comm. on Financial Services, 115th Cong. (June 21, 2018) [hereinafter Clayton Testimony], https://www.sec.gov/news/testimony/testimony-oversight-us-securities-and-exchange-commission [https://perma.cc/6RVS-S7PF] ("We have been clear-we are not relaxing our requirements that apply to the offer, sale and trading of securities."). 
determinations about ICOs and should be cognizant of the far-reaching implications of their decisions. Failing to do so would put form over substance, ignore the economic realities of some ICO transactions, and be judicially and socio-economically problematic. As of June 2018, only one U.S. court has applied Howey to an $\mathrm{ICO}^{27}$ but given the multiple SEC suits and class actions against promoters, the issue is before many courts. ${ }^{28}$

First, in Section II.A, this Comment describes the key features of blockchain technology, categorizes the types of crypto-assets, and provides background on ICOs and tokens, all of which are essential for a securities analysis of token sales. Section II.B summarizes securities laws immediately relevant to this Comment and describes the seminal Howey test for identifying "investment contracts," the catchall for residual types of securities. Section II.C summarizes some of the SEC's notable actions in the ICO space to situate the technology in the current regulatory landscape. In Section III.A, this Comment applies Howey to utility tokens, explaining how and why courts should determine that authentic utility tokens are not necessarily securities. Section III.B presents policy reasons against the broad applicability of securities regulations to ICOs. Lastly, Section III.C argues that tokens should be regulated more like the sale of commodities, or assets like software licenses, gift cards, or (even) gambling chips.

\section{BACKGROUND}

The blockchain is the technological development that makes the creation of crypto-assets and Initial Coin Offerings, among many other applications, possible. ${ }^{29}$ The features that blockchain enables make it both a regulatory challenge and an economic tidal wave, and so, it is important for any lawyer in this space to have a basic grasp on these features. ${ }^{30}$

27. Rensel v. Centra Tech, Inc., No. 17-24500-CIV-KING/SIMONTON, 2018 U.S. Dist. LEXIS 106642, at*12-15 (S.D. Fla. June 25, 2018) (calculating the likelihood of plaintiffs to succeed on the merits in a motion for temporary restraining order against ICO promoters, the judge held with limited analysis that the Centra token was a security). The Eastern District of New York also analyzed an ICO in the commodity context. See Commodity Futures Trading Comm'n v. McDonnell, 287 F. Supp. 3d 213, 213 (E.D.N.Y. 2018).

28. See, e.g., Founder Starcoin, Inc. v. Launch Labs, Inc., No. 18-CV-972 JLS (MDD), 2018 U.S. Dist. LEXIS 113737 (S.D. Cal. July 9, 2018); Baker v. Dynamic Ledger Sols., Inc., No. 17-cv06850-RS, 2018 U.S. Dist. LEXIS 16879 (N.D. Cal. Feb. 1, 2018); GGCC, LLC v. Dynamic Ledger Sols., No. 17-cv-06779-RS, 2018 U.S. Dist. LEXIS 43728 (N.D. Cal. Mar. 16, 2018); In re Tezos Sec. Litig., No. 17-cv-06779-RS, 2018 U.S. Dist. LEXIS 88513 (N.D. Cal. May 25, 2018).

29. See, e.g., Josiah Wilmoth, The Difference Between Utility Tokens and Equity Tokens, STRATEGIC COIN, https://strategiccoin.com/difference-utility-tokens-equity-tokens/ [https://perma.cc/ Y8D6-Y2DD] (last visited Oct. 24, 2018).

30. See Robinson, supra note 7, at 9-11. 
First, Section II.A.1 provides a basic explanation of fundamental blockchain features without delving into their technological underpinnings. Section II.A.2 then distinguishes three categories of blockchain-enabled crypto-assets - cryptocurrencies (like Bitcoin), tokenized securities (or equity tokens), and utility tokens-and briefly describes their unique features. Section II.B focuses on investment contracts: II.B.1 summarizes the SEC's authority and purpose in regulating them and II.B.2 presents the Howey test for classifying offerings as investment contracts. Finally, Section II.C describes recent, important SEC actions that illuminate its stance on ICOs.

\section{A. Blockchain, Crypto-Assets, and Initial Coin Offerings}

"Crypto-assets" is the inclusive term that encompasses all forms of cryptographic, digital assets arising from the use of distributed ledger (blockchain) technology. Although drawing lines between types of crypto-assets is difficult, this Comment, along with many market participants, ${ }^{31}$ suggests putting them in three broad categories: cryptocurrencies (like Bitcoin), tokenized securities (or equity tokens), and utility tokens - the latter two of which will be discussed together in Section II.A.3. Cryptocurrencies and the two types of tokens are technologically extremely similar but have different uses so it is helpful to distinguish them with different terminology.

\section{Blockchains (Distributed Ledger Technology)}

This Section serves to orient readers relatively unfamiliar with blockchain technology (also called "distributed ledger technology") with some of the basic concepts that are essential to understanding what is being offered in an ICO and the regulatory challenge DAPPs pose.

The blockchain concept was widely introduced in a 2009 white paper created by a mysteriously pseudonymous "Satoshi Nakamoto." 32 The title of the paper was "Bitcoin: A Peer-to-Peer Electronic Cash System," which became the basis for the most famous blockchain use-case, Bitcoin. ${ }^{33}$ For

\footnotetext{
31. See, e.g., Unibright.io, Coin vs. Token vs. Security—Regulated?, Medium (Dec. 13, 2017), https://medium.com/@UnibrightIO/coin-vs-token-vs-security-regulated-9e3eb4af6b68 [https://perma.cc/9PR7-LDKM].

32. Julia Finch, From Silk Road to ATMs: The History of Bitcoin, THE GuARDian (Sept. 14, 2017, 2:21 AM), https://www.theguardian.com/technology/2017/sep/13/from-silk-road-to-atms-thehistory-of-bitcoin [https://perma.cc/DQ5F-ANMZ].

33. See Satoshi Nakamoto, Bitcoin: A Peer-to-Peer Electronic Cash System (2009), https://bitcoin.org/bitcoin.pdf [https://perma.cc/6DU6-4PZH].
} 
several years, blockchain was relevant only to its most hardcore acolytes, but through cultural and economic phenomena such as the Silk Road (a dark web anarchy market), ${ }^{34}$ Bitcoin became a widely accepted currency (and speculation tool). ${ }^{35}$ ICOs and DAPP platforms like Ethereum brought the blockchain further into the public eye.

a. Distributed Ledger: Disintermediated Authentication

A blockchain is a network of computational systems ("nodes") for encryption-protected data storage and disintermediated transactionseliminating intermediaries like PayPal, Facebook, or Amazon Web Services when transacting online. ${ }^{36}$ A blockchain is essentially an online peer-to-peer distributed ledger (accounting book), connecting all peer computers to every other peer, obviating the need for a central repository or authority to conduct, log, and authenticate online transactions. ${ }^{37}$ Instead, when a transaction is recorded on one or more network computers, that transaction is reflected on the entire network as the system reconciles the slight addition to its code. ${ }^{38}$

There are many blockchain systems around the world, but the two most culturally and financially significant are Bitcoin ${ }^{39}$ and Ethereum. ${ }^{40}$ Each has a unique value proposition: Bitcoin is primarily an electronic currency and payment platform, ${ }^{41}$ while Ethereum is a blockchain which enables other DAPPs and sub-blockchains (or sub-protocols) to be built upon it, enabling most ICOs. ${ }^{42}$

34. Stephanie A. Lemchuk, Note, Virtual Whats?: Defining Virtual Currencies in the Face of Conflicting Regulatory Guidances, 15 CARDOZO PUB. L. POL'Y \& ETHICS J. 319, 321 (2017).

35. See, e.g., Rob Marvin, Blockchain: The Invisible Technology That's Changing the World, PCMAG (Aug. 29, 2017, 1:38 PM), https://www.pcmag.com/article/351486/blockchain-the-invisibletechnology-thats-changing-the-wor [https://perma.cc/K7E7-S43C].

36. Id.

37. See Enyi \& Le, supra note 14, at 3.

38. See, e.g., Marvin, supra note 35.

39. Bitcoin is the original cryptocurrency and the blockchain that hosts the world's most widely used cryptocurrency: Bitcoins (BTC). Finch, supra note 32.

40. Ethereum hosts the cryptocurrency called Ether, but what makes Ethereum important is that it is also a platform for creating and administering other self-executing programs, often called "smart contracts." Sebastián Peyrott, An Introduction to Ethereum and Smart Contracts: A Programmable Blockchain, AUTH0 (Mar. 28, 2017), https://auth0.com/blog/an-introduction-to-ethereum-and-smartcontracts-part-2/ [https://perma.cc/4STB-L3YJ].

41. Lemchuk, supra note 34 , at 320-24.

42. Enyi \& Le, supra note 14, at 14 n.121. 
b. Smart Contracts: Pre-permissioned Transaction Automation

A "smart contract" is a computer program that automatically executes the terms of an agreement, conducting transactions when certain conditions are met per the "if / then" commands of the code. ${ }^{43}$ Smart contracts are one of the most promising features of blockchain technology because they integrate well with the Internet of Things, ${ }^{44}$ reduce the risk of fraud ${ }^{45}$ decrease arbitration and enforcement transaction costs, ${ }^{46}$ and automate unproductive labor. ${ }^{47}$

c. Immutability and Security: Proof of Work and Mining

Because transactions are recorded on a distributed ledger, no central authority exists to retroactively change past transactions, thus making transactions largely immutable. ${ }^{48}$ The computing power necessary to record these transactions is borne by computers on the network, where the computers cryptographically provide "proof of work" by solving mathematical equations in exchange for small bits of the blockchain's native crypto-asset in a process called "mining."

Only agreement between transacting parties or a consensus of network

43. NiCK SZABO, SMART CONTRACTS (1994), http://www.fon.hum.uva.nl/rob/Courses/ InformationInSpeech/CDROM/Literature/LOTwinterschool2006/szabo.best.vwh.net/smart.contracts .html [https://perma.cc/2JJZ-E56D]; SEC Release, supra note 13, at 2.

44. See, e.g., Jonathan Chester, How Blockchain Startups Will Solve The Identity Crisis For The Internet Of Things, Forbes, https://www.forbes.com/sites/jonathanchester/2017/04/28/howblockchain-startups-will-solve-the-identity-crisis-for-the-internet-of-things/\#6c75ad315c63 (April 28, 2017).

45. See, e.g., Daniel Newman, 3 Ways Blockchain Can Help Combat Fraud (April 17, 2018). https://www.forbes.com/sites/danielnewman/2018/04/17/3-ways-blockchain-can-help-combat-fraud/ \#732c70f092a4.

46. See SZABO, supra note 43.

47. See Alyssa Hertig, What is a DAO?, COINDESK, https://www.coindesk.com/information/ what-is-a-dao-ethereum/ (last visited Oct. 12, 2018).

48. See, e.g., Ramesh Gopinath, Checking the Ledger: Permissioned vs. Permissionless Blockchains, IBM THINK BLOG (July 28, 2016), https://www.ibm.com/blogs/think/2016/07/ checking-the-ledger-permissioned-vs-permissionless-blockchains/ [https://perma.cc/6NH7-BSF9].

49. Commodities Futures Trading Commission, A CFTC Primer on Virtual Currencies, LABCTFC, 5-6 (Oct. 17, 2017), http://www.cftc.gov/idc/groups/public/documents/file/labcftc primercurrencies100417.pdf [https://perma.cc/RAM7-KALL]. 
computing power ${ }^{50}$ can reconcile errant transactions. ${ }^{51}$ No individual can typically control or own a public blockchain once it is activated unless the source code grants special permissions to the creator at the outset. ${ }^{52}$ This is a double-edged sword: hacking and internal fraud are difficult to carry out, but when a problem does arise, it can be difficult to solve.

\section{d. Autonomous Virtual Organizations}

Autonomous virtual organizations are those with sufficient predetermined protocols to operate primarily through smart contracts. ${ }^{53}$ These protocols potentially obviate the need for management or central authority once the blockchain has gone live - a kind of democracy guaranteed by cryptography where changes to the code, and therefore governance, require an endogenous consensus of users rather than application of exogenous force. ${ }^{54}$

\section{e. Pseudonymity: Wallets and Private Keys}

Blockchain transactions do not typically contain directly identifying information about the parties to a transaction. ${ }^{55}$ Instead, parties use "public keys" to identify themselves when conducting transactions. ${ }^{56} \mathrm{~A}$

50. Control on a blockchain is determined by a "consensus" of its users. This consensus can be overridden if one user is able to control over half of all computing power used for the blockchain. Thus, the security of a blockchain increases as more peers join the network. This is called a " $51 \%$ Attack." SEC Release, supra note 13, at 6 n.21; Enyi \& Le, supra note 14, at 4. When there is a hack, such as the fifty million dollars stolen in the DAO hack, blockchain network users will usually "vote" to move their crypto-assets to a new (but nearly identical) blockchain where the code does not recognize the hacker's assets. Hard Fork, INVESTOPEDIA, https://www.investopedia.com/ terms/h/hard-fork.asp [https://perma.cc/53FF-NLRQ] (last visited Oct. 12, 2018). This is called a hard fork. Id. Individuals are free to remain on the original blockchain, but most will choose to conduct future transactions on the new blockchain because the old one has lost much of its value during the exodus. Id.

51. Because of the possibility of a $51 \%$ Attack, the more users of a blockchain, the more computing power it has, the more difficult it is for an entity to take control of the network. Additional users on a blockchain add to its security. See, e.g., Marvin, supra note 35.

52. See generally Lucas Mearian, What Is Blockchain? The Most Disruptive Tech in Decades, COMPUTERWORLD (May 31, 2018, 1:35 PM), https:/www.computerworld.com/article/3191077/ security/what-is-blockchain-the-most-disruptive-tech-in-decades.html?page $=2 \quad$ [https://perma.cc/ TCH4-5YH2].

53. SEC Release, supra note 13 , at 2.

54. See, e.g., Nozomi Hayase, Cryptography as a Democratic Weapon Against Demagoguery, COINDESK (Updated Aug. 8, 2016 3:33 UTC), https://www.coindesk.com/cryptography-democraticweapon-demagoguery/ [https://perma.cc/SKK3-EZS2].

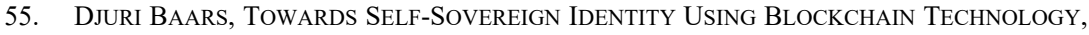
UNIVERSITY OF TWENTE 29, 46, 67, http://essay.utwente.nl/71274/1/Baars_MA_BMS.pdf.

56. Carola F. Berger, Bitcoin Part 3-Hashes, Public Key Cryptography "For Dummies" and the Block Chain, CFB SCI. Translations \& Consulting (June 29, 2015), 
public key is like an address that identifies parties, but only to the extent they make personal information associated with that address available. ${ }^{57}$ As an analogy, think of a public key as an address of a locked PO Box you can ship to and verify delivery. The second component, the "private key," would be the padlock combination (or password) the owner uses to open it. This pseudonymity opens the door to "self-sovereign identity," where some transacting parties hope to more tightly control personal information and maintain a transacting identity outside of government confinesespecially given the global distribution of network users and geospatial quirks of cyberspace. ${ }^{58}$ Pseudonymity is important because it can make tracking down and verifying the identities of individual participants, including blockchain royalty themselves like "Satoshi Nakamoto," extremely difficult.

\section{Cryptocurrency}

Cryptocurrencies (e.g., Bitcoin) are peer-to-peer digital currency networks that get their namesake from the cryptographic, decentralized ledger technology that enables them. ${ }^{59}$ An individual "unit" of cryptocurrency is a "unit of account" and the blockchain is the "medium of exchange" 60 - two central aspects of traditional currencies. Cryptocurrencies are used like an electronically-stored account of fiat money (like a bank database that holds records of peoples' money, rather than the physical money itself) but are actually just a decentralized ledger that tracks and records transactions (the "digital wallet"). ${ }^{61}$ Cryptocurrencies are a libertarian's dream: rather than being necessarily

http://www.cfbtranslations.com/bitcoin-part-3-hashes-public-key-cryptography-for-dummies-andthe-block-chain/ [https://perma.cc/PY4G-FWLL].

57. Id.

58. Antony Lewis, A Gentle Introduction to Self-Sovereign Identity, BITS ON BLOcKs (May 17, 2017), https://bitsonblocks.net/2017/05/17/gentle-introduction-self-sovereign-identity/ [https://perma .cc/RD66-RNFL]; see also BAARS, supra note 55, at 13.

59. See Ken Griffith, A Quick History of Cryptocurrencies BBTC-Before Bitcoin, BITCOIN MAG. (Apr. 16, 2014, 5:10 PM), https://bitcoinmagazine.com/articles/quick-history-cryptocurrenciesbbtc-bitcoin-1397682630/ [https://perma.cc/KE9F-2A5T].

60. See, e.g., Daniel Krawisz, Bitcoin as a Store of Value, Unit of Account, and Medium of Exchange, SATOSHI NAKAMOTO INST. (Jan. 12, 2015), http://nakamotoinstitute.org/mempool/bitcoinas-a-store-of-value-unit-of-account-and-medium-of-exchange/ [https://perma.cc/S7SJ-WABN].

61. David Yermack, Bitcoin Lacks the Properties of Real Currency, MIT TECH. REV. (Feb. 18, 2015), https://www.technologyreview.com/s/524666/bitcoin-lacks-the-properties-of-a-realcurrency/; Mark D. Young, Maureen A. Donley \& Theodore M. Kneller, Bitcoins and the Blockchain: The CFTC Takes Notice of Virtual Currencies, SKADDEN, (Jan. 2016), https://www.skadden.com/ insights/publications/2016/01/bitcoins-and-the-blockchain-the-cftc-takes-notice [https://perma.cc/ H7UK-7J9Z] (last visited Oct. 22, 2018). 
backed by any government's fiat currency or commodity stores (e.g., the gold standard) they reduce the role of central banking and have value simply because people mutually assent to their use in transactions. ${ }^{62}$ Their value is bolstered by network effects and protected by a critical mass of users. $^{63}$ Given their volatility and lack of sovereign or physical-asset backing, there is disagreement whether cryptocurrencies are a "store of value" - a benchmark of traditional currencies. ${ }^{64}$

Cryptocurrency is distinguished from tokens by, unsurprisingly, being designed to act as an external currency (e.g., Bitcoin can be used to buy goods like cars $)^{65}$ whereas a token acts as an internal asset native to a $\operatorname{DAPP}^{66}$ (e.g., Ether, Ethereum's "crypto-fuel" can be used to transact within the platform) ${ }^{67}$

62. Robert J. Anello \& Christina Lee, New-Wave Legal Challenges for Bitcoin and Other Cryptocurrencies, LAW.COM (Nov. 7, 2017), https://www.law.com/sites/almstaff/2017/11/07/newwave-legal-challenges-for-bitcoin-and-other-cryptocurrencies/?slreturn=20180802223437 [https://perma.cc/852G-L4P6].

63. See Primoz Kordez, The Economics of Blockchain Protocols, Medium (Aug. 24, 2017), https://medium.com/@primoz.kordez/the-economics-of-blockchain-protocols-18bca548e596

[https://perma.cc/G8H8-8ZK9]; Marvin, supra note 35; Nicole Vincent Fleming, Staying Current: Bitcoin and Other Cryptocurrencies, Fed. Trade Comm'N Consumer Info. (Sept. 23, 2014), https://www.consumer.ftc.gov/blog/2014/09/staying-current-bitcoin-and-other-cryptocurrencies [https://perma.cc/9HKK-MHBW]. Although usually not backed by any physical assets, some cryptocurrency promoters have fraudulently purported to do so, and others have legitimate plans to be backed by and tied to the price of commodities like oil reserves or precious metals. See, e.g., OilCoin, World's First Legally Compliant Cryptocurrency Backed by Oil, PetroBTC (Jan. 2, 2018), https://petrobtc.com/2018/01/oilcoin-worlds-first-legally-compliant-cryptocurrency-backed-by-oil/ [https://perma.cc/3BMF-BL6W]; Goldcliff Clarifies Gold Based Cryptocurrency Plan, GoLDCLIFF RES. CORP. (Dec. 11，2017，9:00 AM)，https://globenewswire.com/news-release/2017/12/11/ 1250796/0/en/Goldcliff-Clarifies-Gold-Based-Cryptocurrency-Plan.html [https://perma.cc/A9HBWGPX].

64. See, e.g., Yermack, supra note 61.

65. See, e.g., Melanie Hicken, Someone Bought a \$100,000 Tesla with Bitcoins, CNN MONEY (Dec. 12, 2013, 11:49 AM), http://money.cnn.com/2013/12/06/autos/tesla-bitcoin/index.html [https://perma.cc/96PG-SPKJ].

66. See, e.g., John Koetsier, Tim Draper On Bitcoin: 'In 5 Years If You Use Fiat Currency, They Will Laugh At You', FORBES (Nov. 7, 2017), https://www.forbes.com/sites/ johnkoetsier/2017/11/07/tim-draper-on-bitcoin-in-5-years-if-you-use-fiat-currency-they-will-laughat-you/2/\#4c24baa96cfb [https://perma.cc/JGP5-Z5NU]; Nick Grossman, Cryptonetworks and Why Tokens Are Fundamental (March 13, 2018), https://www.nickgrossman.is/2018/cryptonetworks-andwhy-tokens-are-fundamental/ [https://perma.cc/KU3E-APLS].

67. Ether is not intended to be valid tender in the outside world, unlike Bitcoin, but is rather intended to be used by entities within the Ethereum network to purchase computing power to run applications built on top of the Ethereum network. See Ether: The Crypto-Fuel for the Ethereum Network, ETHEREUM, https://www.ethereum.org/ether (last visited Oct. 12, 2018); Rensel v. Centra Tech, Inc., No. 17-24500-CIV-KING/SIMONTON, 2018 U.S. Dist. LEXIS 100720, at*42 n.1 (S.D. Fla. June 14, 2018) ("Ether, on the other hand, is a necessary input, often called the 'native asset,' used to pay the Ethereum platform, a decentralized world computer upon which users can build and run applications, to perform certain tasks.... Ether is generally characterized as a cryptocommodity, rather than a cryptocurrency, but it can and does function like a cryptocurrency in many respects."). 
Many federal agencies are exerting concurrent jurisdiction over cryptocurrencies. $^{68}$ The Commodity Futures Trading Commission steadfastly asserts that cryptocurrencies are commodities. ${ }^{69}$ The Internal Revenue Service has determined they are taxable property. ${ }^{70}$ The SEC points out that cryptocurrency is considered money for the purposes of its regulations. $^{71}$

Cryptocurrencies were the first crypto-assets to catch on, and have done so in a big way: as of mid-December 2017, Bitcoins were collectively worth more than all the securities of Visa or Coca-Cola. ${ }^{72}$ Chicago traders started selling Bitcoin futures in December 2017, treating it like foreign currencies or traditional commodities, ${ }^{73}$ but this speculation is a byproduct rather than a feature of cryptocurrencies. ${ }^{74}$

\section{Initial Coin Offerings (also known as Token Sales)}

ICOs are the online sale of blockchain tokens. Tokens are given in exchange for relatively liquid cryptocurrency (like Bitcoin) or fiat currency in an ICO to fund the development of a distributed ledger project or jump-start an ecosystem of users in a DAPP. ${ }^{75}$ Tokens come with

68. Chris Burniske \& Adam White, Bitcoin: Ringing the Bell for a New Asset Class, ARK INVEST, https://ark-invest.com/research/bitcoin-new-asset-class [https://perma.cc/JNK7-4DKU] (scroll down and click “download white paper") (last updated Jan. 2017).

69. In the Matter of Coinflip, Inc., CFTC Docket No. 15-29, at 3 (Sept. 17, 2015), https:/www.cftc.gov/sites/default/files/idc/groups/public/@1renforcementactions/documents/legalpl eading/enfcoinfliprorder09172015.pdf [https://perma.cc/M2BP-ANR6].

70. INTERNAL REVENUE SERV., IRS VIRTUAL CURRENCY GUIDANCE: ViRTUAL CURRENCY IS Treated as Property for U.S. Federal Tax Purposes; General Rules for Property TRANSACTIONS APPLY (March 25, 2014), https:www.irs.gov/uac/Newsroom/IRS-Virtual-CurrencyGuidance [https://perma.cc/9AQ9-C6AR].

71. SEC Release, supra note 13, at 11 (citing SEC v. Shavers, 2014 WL 4652121, at *1 (E.D. Tex. Sept. 18, 2014) (holding that bitcoin was money for the purposes of Howey)); see also Uselton v. Comm. Lovelace Motor Freight, Inc., 940 F.2d 564, 574 (10th Cir. 1991).

72. Kim Jaewon, South Korea Joins in Asia-Wide Bitcoin Crackdown, NIKKEI ASIAN REV. (Dec. 14, 2017, 10:00 AM), https://asia.nikkei.com/Economy/South-Korea-joins-in-Asia-widebitcoin-crackdown [https://perma.cc/7E8K-YP7X].

73. Makortoff, supra note 2.

74. Marissa Lee, Bitcoin and the Art of Market Manipulation: An Inquiry into Value, THE Bus. TIMES SING. (Dec. 18, 2017, 5:50 AM) [hereinafter Bus. Times Sing.] https://www.businesstimes.com. sg/banking-finance/bitcoin-and-the-art-of-market-manipulation-an-inquiry-into-value [https://perma. cc/8W3Q-ZF3W] ("[T]he level of professional attention springing up around bitcoin says nothing about the digital token's intrinsic value. Bitcoin is a great proof of concept for blockchain technology, and has so far been a great trading opportunity. As a substitute for fiat currency or a store of value however, it makes a weak case. Very simply, exchanges are pressing ahead with bitcoin futures because it is a lucrative business.').

75. See generally CoinBase, A Securities Law Framework for Blockchain Tokens (last updated Dec. 7, 2016) [hereinafter CoinBase] https://www.coinbase.com/legal/securities-law-framework.pdf [https://perma.cc/Y9TZ-DKGR] (explaining the best practices in token sales and relevant legal 
various rights and features and may or may not purport to confer any actual ownership interest or voting power in an organization. ${ }^{76}$ Tokens are essentially the internal cryptocurrency of the blockchain on which they are issued and may have resale value on secondary markets. ${ }^{77}$ The value of these tokens largely derives from the perceived functional utility of the token and expectations of its future value, commensurate to the DAPP's stage of development. ${ }^{78}$ Tokens are also called protocol tokens, app coins, or coins, among other names.

There are two broad categories of tokens: equity tokens and utility tokens. ${ }^{79}$ Not everyone agrees that drawing such a distinction between the two types is practical nor do all agree on specific terminology. ${ }^{80}$ The lines between the two are blurred, and token promoters often purport to sell a "utility token" when their offer functions as little more than a fundraising vehicle. $^{81}$ Because labels are not dispositive, thoughtfully drawing distinctions is key to determining whether a token sale is the sale of a security.

\section{a. Tokenized Securities}

Tokenized securities, also termed security tokens or equity tokens, ${ }^{82}$ are stand-ins for shares of corporate stock or startup equity, ${ }^{83}$ with their value tied to the value of the issuing organization (or the blockchain application the token is native to). A tokenized security, like stock of a

analysis surrounding Blockchain tokens).

76. Id. at 9-10; See also Nicolas Morgan, David M. Hernand \& Vivian Tsai, A Light Regulatory Touch on Initial Coin Offerings, LAw360 (Aug. 1, 2017), https://www.law360.com/articles/950189/alight-regulatory-touch-on-initial-coin-offerings [https://perma.cc/VA5H-HPK2].

77. See Morgan, Hernand \& Tsai, supra note 76.

78. Pesok \& Brylski, supra note 21. Unfortunately, opportunists have leveraged the cryptomania surrounding ICOs to manipulate the public by "guaranteeing" returns and utilizing celebrity endorsements like Paris Hilton, among others. Palmer, supra note 3. This, along with security concerns, has made government involvement essential. China, for example, has gone as far as banning ICOs altogether. Bus. Times Sing., supra note 74.

79. Wilmoth, supra note 29; see also Shin, supra note 11; Robert Smith, The Rise of the Utility Token, NEWSBTC (Sept. 12, 2017, 2:30 PM), http:/www.newsbtc.com/2017/09/12/rise-utility-token/ [https://perma.cc/LG4Q-TQWE]; Micha Benoliel, Understanding the Difference between Coins, Utility Tokens, and Tokenized Securities, MEDIUM (Aug. 8, 2017), https://medium.com/startupgrind/understanding-the-difference-between-coins-utility-tokens-and-tokenized-securitiesa6522655fb91 [https://perma.cc/QU3D-X6YR].

80. Shin, supra note 11.

81. See, e.g., Benoliel, supra note 79; see also Hinman, supra note 26.

82. See Wilmoth, supra note 29. "Security token" is technically a broader term than "equity token," with the former encompassing the latter. Id. A security token is securitized by an asset as collateral like real estate, gold, or equity in an entity. Id.

83. See, e.g., Benoliel, supra note 79; Brownell, supra note 10. 
public corporation, can typically be resold on secondary markets for a profit if the value increases, ${ }^{84}$ unlike with traditional venture capital where interests are not easily alienable. Usually, equity tokens have little-to-no utility beyond conferring a right to future profits of the issuing organization or, more commonly, the promise of appreciation of the token itself. $^{85}$ The circumstances of such "promises" and the structure of the DAPP are the major determinants of whether a crypto-asset is a tokenized security. ${ }^{86}$ Tokenized securities can come with additional rights, like the ability to vote on uses for the pooled funds or actual (or constructive) ownership in an entity, ${ }^{87}$ but ultimately these rights exist to support the primary purpose of raising funds to be used or controlled by a third party or the issuer. ${ }^{88}$

The sale of equity tokens is a trendy and relatively easy way to raise capital. Unfortunately, many sales of these crypto-assets run counter (or at least orthogonal) to the spirit of an autonomous organization designed to run on a blockchain - instead using the ICO mechanism to skirt securities laws or otherwise nefariously abuse ICO-mania. ${ }^{89}$ There is general agreement that the sale of tokenized securities in an ICO constitutes the sale of securities. ${ }^{90}$

\section{b. Utility Tokens}

The second kind of tokens are utility tokens (also termed user tokens or DAPP tokens). ${ }^{91}$ Utility tokens can be tradeable on secondary markets

84. See Wilmoth, supra note 29. Additionally, equity tokens can represent debt owed by the company to the token holder, creating a market for micro-loans to businesses. Id. These securities would likely be considered "notes" rather than "investment contracts" and is beyond the scope of this Comment.

85. Shin, supra note 11.

86. See Hinman, supra note 26.

87. Wilmoth, supra note 29.

88. Voting rights can actually make an offering look more like a security rather than less. See Landreth Timber Co. v. Landreth, 471 U.S. 681, 686 (1985) ("[W] concluded that we must also determine whether those instruments possess 'some of the significant characteristics typically associated with' stock recognizing that when an instrument is both called 'stock' and bears stock's usual characteristics, 'a purchaser justifiably [may] assume that the federal securities laws apply'. We identified those characteristics usually associated with common stock as (i) the right to receive dividends contingent upon an apportionment of profits; (ii) negotiability; (iii) the ability to be pledged or hypothecated; (iv) the conferring of voting rights in proportion to the number of shares owned; and (v) the capacity to appreciate in value." (citations omitted)).

89. See generally Marco Santori, Appcoin Law: ICOs the Right Way, COINDESK (Oct. 15, 2016, 4:04 PM), https://www.coindesk.com/appcoin-law-part-1-icos-the-right-way/ [https://perma.cc/ CS5B-QHRS].

90. See, e.g., Hinman, supra note 26.

91. See Cryptographic Tokens, BlockchainHub (last accessed Oct. 12, 2018), 
and appreciate like tokenized securities, but primarily exist to integrate into the blockchain application they are issued for. Utility tokens, like Ethereum's Ether, ${ }^{92}$ are often used as a currency internal to the DAPP and are the grease in the wheels of an incentive structure created to promote beneficial behavior on the DAPP. ${ }^{93}$ The token's existence is essential to the functioning of the system, ${ }^{94}$ like a decentralized cloud-storage application ${ }^{95}$ that allows people to trade excess storage capacity on their computer systems for tokens. ${ }^{96}$ In that example, although the utility token may appreciate as the usefulness of the application is proved, its primary function is as an internal currency that incentivizes people to buy and sell excess storage capacity on their computers in exchange for tokens. Simply put, utility tokens have "consumptive use value or a commercial purpose,, 97 and are not fundamentally intended to be relied on as a passive investment vehicle. ${ }^{98}$ Utility tokens can be used on the application to engage in transactions and earn rewards, while increasing the value of the network (and therefore the token at resale) due to network effects. ${ }^{99}$ Utility tokens have been compared to gambling chips, ${ }^{100}$ tradable gift cards, ${ }^{101}$ (pre-sold) software licenses, ${ }^{102}$ franchise agreements, ${ }^{103}$ sporting event tickets, ${ }^{104}$ and more.

The concept of utility tokens aligns with the essence of blockchain technology: pseudonymous actors interacting in a distributed ecosystem

https://blockchainhub.net/tokens/ [https://perma.cc/23LV-SCZ5].

92. See, e.g., Hinman, supra note 26 ("And putting aside the fundraising that accompanied the creation of Ether, based on my understanding of the present state of Ether, the Ethereum network and its decentralized structure, current offers and sales of Ether are not securities transactions.").

93. See generally STEEM, https://steem.io [https://perma.cc/3589-PRR6] (last visited Oct. 12, 2018) (demonstrating the blockchain social networking application, Steem, grants tokens to those who create and promote quality content.).

94. Kordez, supra note 63.

95. Protocol Labs, Filecoin: A Decentralized Storage Network, FILECOIN, at 1 (July 19, 2017) [hereinafter Filecoin], https://filecoin.io/filecoin.pdf [https://perma.cc/XJ2P-J7T8].

96. Id.

97. Shin, supra note 11. Compare utility tokens to Pokémon cards. The intended use of Pokémon cards is to engage in Pokémon battles with friends, even though some collectors purchase and hold onto them with the hopes their value will appreciate over time.

98. CoinBase, supra note 75 , at 22 .

99. Kordez, supra note 63.

100. Enyi \& Li, supra note 14.

101. Lindsay Lin, Why ICOs Should Want to Be Securities, CoINDESK (October 2, 2017) [hereinafter Why ICOs Should Want to Be Securities] https://www.coindesk.com/icos-want-securities/ [https://perma.cc/QPM2-4SD2].

102. Id.

103. CoinBase, supra note 75, at 20-22.

104. See Wilmoth, supra note 29 (comparing utility token price fluctuations to that of sporting event tickets). 
designed to promote mutually beneficial behavior with the token acting as an internal currency. SEC Chairman Jay Clayton stated that he has yet to see any ICOs that are not the sale of securities, including those that purport to be utility token sales. ${ }^{105}$ However, the SEC has acknowledged the possible existence of non-security utility tokens, focusing on the digital consumer's motivations and structure of the DAPP in categorizing them. ${ }^{106}$

As argued in Part III, utility tokens should not be considered securities but rather as items for consumptive and commercial use because of their usability as native digital assets integral to the underlying application, the reasonable motivation of purchasers, the importance of network effects, and the negative policy implications of applying securities regulations to utility tokens.

\section{B. Investment Contracts}

The Securities Act of 1933 Section 2(1) defines a "security" as any "note, stock, treasury stock . . . , bond, debenture, evidence of indebtedness, certificate of interest or participation in any profit-sharing agreement, collateral-trust certificate, preorganization certificate or subscription, transferable share, investment contract, voting-trust certificate, certificate of deposit for a security, . . . [and more]." ${ }^{107}$ This Section will first provide background on the Securities Act, then describe the Howey test that courts use to classify investment contracts, and finally summarize how the SEC has applied this test in its first few actions.

\section{The SEC}

The purpose of the SEC, an independent federal administrative agency, "is to protect investors, maintain fair, orderly, and efficient markets, and facilitate capital formation."108 The SEC, under

105. E.g., David N. Feldman, SEC Chair Clayton Comments on Initial Coin Offerings (ICOs), DUANE MORRIS BLOGS (Nov. 10, 2017), https://blogs.duanemorris.com/capitalmarkets/ 2017/11/10/sec-chair-clayton-comments-on-initial-coin-offerings-icos/ [https://perma.cc/7CZ2A447]; David Michaels \& Paul Vigna, SEC Chief Fires Warning Shot Against Coin Offerings, WALL STREET J. (Nov. 9, 2017), https://www.wsj.com/articles/sec-chief-fires-warning-shot-against-coinofferings-1510247148.

106. See Hinman, supra note 26 ("[T] $]$ here are contractual or technical ways to structure digital assets so they function more like a consumer item and less like a security."). Near the end of his speech, Director Hinman provides a non-exhaustive list of considerations. Id.

107. 15 U.S.C. $\S 77 b(a)(1)$ (2012) (emphasis added).

108. What We Do, U.S. SEC. \& EXCH. COMM'N, https://www.sec.gov/Article/whatwedo.html [https://perma.cc/SJB8-434D] (last visited Sept. 9, 2018) [hereinafter What We Do]. 
Congressional authorization, investigates and prosecutes securities violations in interstate (online) commerce, particularly to protect "Main Street" and institutional investors. ${ }^{109}$

The vast majority of relevant SEC authority derives from the Securities Act of 1933 and the Securities Exchange Act of 1934, of which the legislative purpose is to "eliminate serious abuses in a largely unregulated securities market . . . to prevent fraud and to protect the interest of investors." 110 In exercising power over the initial issuance of tokens, the SEC derives its authority from the Securities Act of 1933, ${ }^{111}$ which defines a security as any disposition of an "investment contract," among other things. ${ }^{112}$

The Securities Act of 1933 was enacted to restore investor confidence following the stock market crash of 1929 and has been updated as recently as the Jumpstart Our Business Startups (JOBS) Act in 2012. ${ }^{113}$ The acts impose disclosure-focused statutory prospectus and registration requirements on any person offering securities in the United States to promote a more informed investing public. ${ }^{114}$

Unless there is an applicable exemption to registration, it is illegal to sell unregistered securities in the United States. ${ }^{115}$ The risks of noncompliance with securities registration requirements are severe, including fines, rescission of sales, cease-and-desist orders, bans from market participation, or five years imprisonment under Section 5 of the Securities Act (plus private causes of action under Sections 12(a)(1) and 17(a)(1) of the Act.) $)^{116}$ Additionally, the SEC Office of Investor Education

109. See Clayton Testimony, supra note 26 ("I am very optimistic that developments in financial technology, including distributed ledger technology, will help facilitate capital formation, providing promising investment opportunities for institutional and Main Street investors alike.").

110. United Hous. Found., Inc. v. Forman, 421 U.S. 837, 849 (1975).

111. 15 U.S.C. $\S 77 b(2012)$.

112. Id. § $77 \mathrm{~b}(\mathrm{a})(1)$.

113. 1 K\&L Gates, SeCurities Practice Guide $\S \S 1.01,2.01$ (2018).

114. Id. § 1.01 .

115. See generally Santori, supra note 89; SEC Release, supra note 13, at 10 ("Section 5(a) of the Securities Act provides that, unless a registration statement is in effect as to a security, it is unlawful for any person, directly or indirectly, to engage in the offer or sale of securities in interstate commerce.”). There is no scienter requirement. SEC v. Universal Major Indus. Corp., 546 F.2d 1044, 1047 (2d Cir. 1976) (finding that negligent selling of unregistered securities alone is sufficient, thus no scienter requirement).

116. Why ICOs Should Want to Be Securities, supra note 101. Even if a token avoids federal securities regulations, it may still be subject to state-specific "blue sky" laws. Id. See also Fast Answers: Blue Sky Laws, U.S. SEC. \& EXCH. COMM'N (last modified Oct. 14, 2014), https://www.sec.gov/fast-answers/answers-blueskyhtm.html [https://perma.cc/JK5F-QL63]; Peter M. Saparoff, John F. Nucci \& Joel D. Rothman, Private Placement Securities Litigation, AM. BAR. Ass'N. (September 9, 2015), https://www.americanbar.org/groups/litigation/committees/securities/articles/ 2015/summer2015-0815-private-placement-securities-litigation/ [https://perma.cc/C8H3-TFZ7]. 
protects the public by producing and sharing educational materials for investors, ${ }^{117}$ including a July 25, 2017 Investor Bulletin that gives advice to anyone considering participating in an ICO. ${ }^{118}$ In September 2017, the SEC announced the creation of a Cyber Unit, FinTech Working Group, and Distributed Ledger Technology Working Group within its Enforcement Division to approach novel regulatory challenges like ICOs. ${ }^{119}$

In addition to bringing actions against issuers for the unregistered sale of securities, the SEC commonly brings actions for fraud against disingenuous promoters. These consumer protections have been important in the ICO space, as bad actors try to cash in on the cryptomania. For example, the SEC Cyber Unit brought fraud charges against a serial securities-laws violator who raised $\$ 15$ million through an $\mathrm{ICO}^{120}$ and two promoters of ICOs falsely claiming to be backed by real estate and diamonds. ${ }^{121}$

Promoters may avoid compliance with most securities requirements, other than anti-fraud provisions, if the instrument qualifies and the promoter applies for an exemption to registration. Many issuers may choose to issue tokens under Regulation D (the private-placement-toaccredited-investors), ${ }^{122}$ Regulation S (the offshore-offers-and-sales-safe-

117. What We Do, supra note 108.

118. Investor Bulletin: Initial Coin Offerings, U.S. SEC. \& EXCH. COMM’N (July 25, 2017), https://www.sec.gov/oiea/investor-alerts-and-bulletins/ib_coinofferings [https://perma.cc/BT53NA8M].

119. SEC Announces Enforcement Initiatives to Combat Cyber-Based Threats and Protect Retail Investors, U.S. SEC. \& EXCH. COMM'N (Sept. 25, 2017), https://www.sec.gov/news/pressrelease/2017-176 [https://perma.cc/L8GD-8RFG]; See Clayton Testimony, supra note 26.

120. Stan Higgins, SEC Files Fraud Charges Against ICO Organizer, CoINDESK (Dec. 4, 2017, 2:35 PM), https://www.coindesk.com/sec-files-fraud-charges-canadian-ico-organizer/ [https://perma. cc/U3JP-352U].

121. SEC Exposes Two Initial Coin Offerings Purportedly Backed by Real Estate and Diamonds, U.S. SEC. \& EXCH. COMM'N (Sept. 29, 2017), https://www.sec.gov/news/press-release/2017-185-0 [https://perma.cc/L73S-ZNV8]; Complaint, SEC v. ReCoin, 17 Civ. 5725 (E.D.N.Y. Sept. 29, 2017), https://www.sec.gov/litigation/complaints/2017/comp-pr2017-185.pdf [https://perma.cc/3KBU23PD]; see also Litigation Release No. 24081, U.S. SEC. \& EXCH. COMM'N (Mar. 26, 2018) https://www.sec.gov/litigation/complaints/2017/comp-pr2017-185.pdf [https://perma.cc/Z64T$\mathrm{KN} 4 \mathrm{Q}]$.

122. Shelley Goldberg, Expanding the Definition of “Accredited Investor", WALL STREET DAILY (Feb. 25, 2016), https://www.wallstreetdaily.com/2016/02/25/accredited-investor-private-equity/ [https://perma.cc/E9FS-GBKU]; Investor Bulletin: Private Placements Under Regulation D, U.S. SEC. \& EXCH. COMM'N (Sept. 24, 2014), https://www.investor.gov/additional-resources/newsalerts/alerts-bulletins/investor-bulletin-private-placements-under [https://perma.cc/VKJ2-EMJS]; Gregory J. Nowak \& Joseph C. Guagliardo, Blockchain and Initial Coin Offerings: SEC Provides First U.S. Securities Law Guidance, HARV. L. SCH. F. ON CORP. GOVERNANCE \& Fin. REG. (Aug. 9, 2017), https://corpgov.law.harvard.edu/2017/08/09/blockchain-and-initial-coin-offerings-sec-provi des-first-u-s-securities-law-guidance/ [https://perma.cc/XB5K-CT2C]. 
harbor), ${ }^{123}$ Regulation A (small-and-additional-issues-of-securities), ${ }^{124}$ and Regulation Crowdfunding ${ }^{125}$ exemptions rather than face compliance with initial public offering requirements, although each has important limitations and legal requirements. ${ }^{126}$

The role of the federal court is to "decide which of the myriad financial transactions in our society come within the coverage of these statutes."127 Here, that is whether an instrument fits within the definition of "security." Courts generally give weight to the SEC's interpretations of a statute it is responsible for administering, but its ultimate deference is to the clear meaning of the statute. Deference increases when an agency follows a formal rule-making process. ${ }^{128}$

In all enforcement actions against unregistered ICOs to date, the SEC has sought to categorize tokens as securities by attesting they are investment contracts under Howey. As of October 2018, no appellate federal court has ruled on whether and when an ICO of a legitimate utility token constitutes an investment contract (or security generally). Although largely beyond the scope of this Comment, it is important to recognize that the Howey test, although the likely battleground for much ICO securities litigation, is not the sole test used for determining whether an offering is a

123. U.S. SEC. \& EXCH. COMM'N, Final Rule: Offshore Offers and Sales (Regulation S), Release Nos. 33-7505, 34-39668, https://www.sec.gov/rules/final/33-7505.htm [https://perma.cc/ZVC9DD69]; Jor Law, Don't Panic! US Securities Exemptions for Initial Coin Offerings, CROWDFUND INSIDER (Aug. 21, 2017, 8:00 AM), https://www.crowdfundinsider.com/2017/08/120850-dont-panicus-securities-exemptions-initial-coin-offerings/ [https://perma.cc/L4PH-D9DL].

124. U.S. SEC. \& EXCH. COMM'N, Amendments for Small and Additional Issues Exemptions under the Securities Act (Regulation A), Release Nos. 33-9471; 34-74578; 39-2501, https://www.sec.gov/rules/final/2015/33-9741.pdf [https://perma.cc/4YCN-8BZ4].

125. U.S. SEC. \& EXCH. COMM'N, Regulation Crowdfunding: A Small Entity Compliance Guide for Issuers (Apr. 5, 2017), https://www.sec.gov/info/smallbus/secg/rccomplianceguide-051316.htm [https://perma.cc/3YWW-3WLH]. Title III of the JOBS Act added section 4(a)(6) to the Securities Act allows for the exemption from registration for some crowdfunding transactions. Id. According to the SEC, "[c]rowdfunding is a relatively new and evolving method of using the Internet to raise capital ... through ... small individual contributions from a large number of people ... [where] [i]ndividuals ... may share information about the project, cause, idea or business ... to decide whether to fund the campaign based on the collective "wisdom of the crowd." Id. at n.2.

126. Why ICOs Should Want to Be Securities, supra note 101. For further reading on securities exemption in the ICO context see, jrlmaker, Securities Exemptions for ICOs https://steemit.com/crypto-news/@jrlmaker/securities-exemptions-for-icos [https://perma.cc/WV22DBDC] (last visited Oct. 26, 2018)

127. Reves v. Ernst \& Young, 494 U.S. 56, 61 (1990) (citations omitted).

128. See CFTC v. McDonnell, 287 F. Supp. 3d 213, 224 (E.D.N.Y. 2018); CFTC v. Sterling Trading Grp., Inc., 605 F. Supp. 2d 1245, 1265-66 (S.D. Fla. 2009) (citing TVA v. Whitman, 336 F.3d 1236, 1250 (11th Cir. 2003)) ("Chevron deference is confined to those instances in which the agency renders its interpretation in the course of a rulemaking proceeding or adjudication .... [E]ven if an agency's interpretation of its own statute is advanced in the course of litigation rather than through a rulemaking or agency adjudication, courts will still pay some deference to the agency's interpretation.”). 
security. States may apply their own investment contract tests, like the Risk Capital Test, for the purposes of their own state securities laws. ${ }^{129}$ Further, ICOs could potentially fall into another subcategory of security, like a note, and thus be subject to alternative tests such as the Family Resemblance Test. ${ }^{130}$ The following Section presents the Howey test as it currently stands.

\section{The Howey Test}

In determining whether an offering constitutes an "investment contract," federal courts look to the common law and apply a test set forth in the 1946 Supreme Court case of SEC v. W.J. Howey Co. and its progeny. ${ }^{131}$

The Howey Court defined an investment contract as a "scheme whereby a person invests his money in a common enterprise and is led to expect profits solely from the efforts of the promoter or a third party"132 and the definition "embodies a flexible rather than a static principle, one that is capable of adaptation to meet the countless and variable schemes devised by those who seek the use of the money of others on the promise of profits." 133 Securities are meant to include any instrument that falls within society's commercial conception of a security so that passive investors are protected. ${ }^{134}$ The Court has broadly construed investment contracts to include "novel, uncommon, or irregular devices"135 in

129. Courts in several states, including California and Michigan, use the four-pronged test, the Risk Capital Test to identify securities. 3 Common Misconceptions, supra note 11. First, the issuer must raise money for an enterprise. $I d$. Second, the issuer must indiscriminately offer the fundraising opportunity to the public at large. $I d$. Third, the investor must be only in a passive position to affect the enterprise's success. Id. Fourth, the investor's contribution must be inadequately secured and substantially at risk. Id. Essentially, if a widely offered investment opportunity is sufficiently risky, it will trigger securities laws protections. Id. See generally Silver Hills Country Club v. Sobieski, 55 Cal. 2d 811 (1961) (pre-purchased club memberships were risk capital because the country club had not been built and therefore investors were at a high risk of loss). This test is often applied in the context of start-up capitalization before a product or service has been built. See CoinBase, supra note 75, at 16. See also Jet Set Travels Club v. Corp. Comm'r, 21 Or. App. 362 (1975). This test may apply regardless of whether an ICO issuer escapes SEC enforcement. Why ICOs Should Want to Be Securities, supra note 101.

130. See generally, Reves, 494 U.S. 56; 3 Common Misconceptions, supra note 11.

131. See generally, SEC v. Edwards, 540 U.S. 389 (2004).

132. SEC v. W. J. Howey Co., 328 U.S. 293, 298-99 (1946).

133. Edwards, 540 U.S. at 393 (citations omitted).

134. United Hous. Found., Inc. v. Forman, 421 U.S. 837, 847-48 (1975) (citing H.R. Rep. No. 85, 73d Cong., 1st Sess., 11 (1933)).

135. See SEC v. C. M. Joiner Leasing Corp., 320 U.S. 344, 351 (1943) ("[T]he reach of the [Securities] Act does not stop with the obvious and commonplace.”). 
"whatever form they are made and by whatever name they are called."136 The court focuses on the economic realities underlying the transaction and puts substance over form-regardless of the use of technology in the offerings. ${ }^{137}$ The Howey test will be broken into constituent parts below. "An offering is an investment contract if there is: (1) an investment of money (2) in a common enterprise (3) with the expectation of profits to come solely from the efforts of others." 138

a. The Investment of Money

The first prong of the Howey test, investment of money, is construed broadly and exists to protect investors from financial loss-including cash, goods, notes, or other assets. Courts have concluded that cryptocurrencies can constitute investments of money. ${ }^{139}$ Because tokens are typically given in exchange for cryptocurrency or fiat money, any such ICO can rightly be considered an investment of money. ${ }^{140}$

\section{b. In a Common Enterprise}

The U.S. Supreme Court has not made a specific ruling on the "common enterprise" prong of Howey, but lower courts have taken different approaches to how the common enterprise prong is met. ${ }^{141}$

First is the "horizontal approach" where courts examine whether individual investors' fortunes are tied to those of the other investors in a scheme. ${ }^{142}$ Generally, if there is a pooling of funds, courts will find there

136. See Reves v. Ernst \& Young, 494 U.S. 56, 61 (1990) (“Congress' purpose in enacting the securities laws was to regulate investments, in whatever form they are made and by whatever name they are called." (emphasis omitted)).

137. See C. M. Joiner Leasing Corp., 320 U.S. at 352-53.

138. Rensel v. Centra Tech, Inc., No. 17-24500-CIV-KING/SIMONTON, 2018 U.S. Dist. LEXIS 106642, at *13 (S.D. Fla. June 25, 2018) (quoting Tippens v. Round Island Plantation LLC, No. 09-CV-14036-MOORE/LYNCH, 2009 U.S. Dist. LEXIS 66224, at*9 (S.D. Fla. July 31, 2009)).

139. SEC v. Shavers, No. 4:13-CV-416, 2014 WL 4652121, at *8 (E.D. Tex. Sept. 18, 2014) (holding that bitcoin was money for the purposes of Howey); see Uselton v. Commercial Lovelace Motor Freight, Inc., 940 F.2d 564, 574 (10th Cir. 1991) (extending the investment prong to include an "exchange of value" including the provision of goods and services). Crypto-assets are sometimes given in exchange for borrowed computing power (via a process called "mining"). Santori, supra note 89; CoinBase, supra note 75, at 24. This is beyond the scope of this Comment because the types of ICOs contemplated are capital formation devices that exchange tokens for money.

140. SEC Release, supra note 13, at 11. A more difficult question arises in the "mining" context, where participants contribute computing power (and significant electricity) in exchange for cryptoassets.

141. K\&L GATES, supra note $113, \S 2.03$.

142. CoinBase, supra note 75, at 13; Curran v. Merrill Lynch, Pierce, Fenner \& Smith, Inc., 622 F.2d 216, 221-22 (6th Cir. 1980). 
is a common enterprise under this approach. ${ }^{143}$ Arrangements do not fit the horizontal enterprise requirement if they are structured more like general partnerships than limited partnerships. ${ }^{144}$

Alternatively, under the "vertical approach" (sometimes split into "narrow vertical" and "broad vertical"), ${ }^{145}$ courts look instead to the link between the fortunes of the investor and the promoter. ${ }^{146}$ Where returns are interwoven and dependent on the actions ${ }^{147}$ or expertise ${ }^{148}$ of the promoter, a common enterprise will be found. Theoretically, if a promoter creates a truly decentralized autonomous organization where the value of the instrument relies primarily on the beneficial actions of the other holders rather than the promoters and their agents, there is no vertical common enterprise. ${ }^{149}$ Additionally, a DAPP developed and launched before conducting an ICO may indicate a lack of dependence of token buyers on the continued efforts of the promoter. ${ }^{150}$

c. With the Reasonable Expectation of Profits

The "reasonable expectation of profits" prong of Howey refers to the expectation of the buyer as to what she will receive for her investment. ${ }^{151}$ To meet this prong, the transaction must be premised on the expectations of profits. ${ }^{152}$ Generally, "profits" refer to the increase in value (fixed or variable) of an investment through dividends, periodic payments, appreciation of the instrument, or similar means. ${ }^{153}$ The expectation of profit must be the primary, but need not be the sole motivation for the investment. ${ }^{154}$ If purchasers are motivated by a desire to consume the purchased item, then securities laws do not apply. ${ }^{155}$ Additionally, a contributor's expectation of appreciation of their investment may not be the primary reason for her contribution; she may have personal or

\footnotetext{
143. K\&L GATES, supra note $113, \S 2.03$.

144. For a thorough discussion on this point, see Robinson, supra note 7, at 44-45.

145. CoinBase, supra note 75, at 13.

146. SEC v. Eurobond Exch. Ltd., 13 F.3d 1334, 1339 (9th Cir. 1994).

147. Id. This is the narrow vertical approach. CoinBase, supra note 75, at 13 .

148. SEC v. Cont'l Commodities Corp., 497 F.2d 516, 522 (5th Cir. 1974). This is the broad vertical approach. CoinBase, supra note 75, at 13.

149. See Robinson, supra note 7, at 38-40; CoinBase, supra note 75, at 13-14.

150. See generally Hinman, supra note 26.

151. SEC v. Edwards, 540 U.S. 389, 395-96 (2004); K\&L GATES, supra note 113, § 2.03.

152. See Int'l Bhd. of Teamsters v. Daniel, 439 U.S. 551, 561 (1979) (emphasis added) (citing United Hous. Found., Inc. v. Forman, 421 U.S. 837, 852 (1975)).

153. Edwards, 540 U.S. at 394; CoinBase, supra note 75, at 16-17.

154. Santori, supra note 89.

155. Forman, 421 U.S. at 852-53.
} 
commercial purposes. ${ }^{156}$ For example, the Court has held that cooperative apartment buy-ins were not securities, even where resale value was expected to increase, because a purchaser's primary motivation in contributing was to acquire a place to live. ${ }^{157}$

As discussed in Section III.A.2, utility tokens may function more like an apartment co-op if the purpose of the holder is to use the token for personal or commercial reasons and appreciation is an expected byproduct - like a person buying a Beanie Baby (or Cryptokitty). ${ }^{158}$

Courts typically view this prong through the lens of the Howey test's fourth prong: whether the expectation of profits arises from the promoters or from third parties engaging in the acts that create the returns for the holder. ${ }^{159}$ Marketing materials, including third-party comments ratified by the promoter, have been extremely important in priming the expectations of buyers. For example, the SEC has indicated that advertising or promising a secondary market for the resale of tokens lead to an expectation that buyers are purchasing a security, as described in Section II.C.2. If the expectations of the contributor are similar to those of a contributor making a passive investment, then this prong will probably be satisfied. ${ }^{160}$

\section{d. Derived from the Efforts of Others}

The original wording of Howey's final prong required that the expectation of profits arise "solely" from the efforts of others, but the language has since been broadened. ${ }^{161}$ The standard is now whether "the efforts made by those other than the investor are the undeniably significant ones, those essential managerial efforts which affect the failure or success

156. See Daniel, 439 U.S. at 553 (“And with respect to the expectation-of-profits element, while the pension fund depends to some extent on earnings from its assets, the possibility of participating in asset earnings is too insubstantial to bring the entire transaction within the Securities Acts.").

157. Forman, 421 U.S. at 858 ("There is no doubt that purchasers in this housing cooperative sought to obtain a decent home at an attractive price. But that type of economic interest characterizes every form of commercial dealing. What distinguishes a security transaction - and what is absent here-is an investment where one parts with his money in the hope of receiving profits from the efforts of others, and not where he purchases a commodity for personal consumption or living quarters for personal use.").

158. Tim Marcin, What Are Cryptokitties? Latest Craze Involves Virtual Cats Selling For $\$ 100,000$ on Ethereum Blockchain, NEWSWEEK (Dec. 7, 2017, 3:15 PM), https://www.newsweek.com /what-are-cryptokitties-virtual-cats-sold-millions-dollars-ethereum-blockchain-741525 [https://perma.cc/262N-ANYU].

159. CoinBase, supra note 75 , at 17.

160. Id.

161. SEC v. Glenn W. Turner Enters., Inc. 474 F.2d 476, 481-83 (9th Cir. 1973). 
of the enterprise."162 In other words, courts examine whether the success of a common enterprise necessarily arises from the significant managerial, entrepreneurial, or other efforts of the promoter or third party. ${ }^{163}$ It is unclear whether reliance on the actions of other token-holders would satisfy this prong. That determination would depend on the rights and interests that a token confers and the features of the relevant DAPP. ${ }^{164}$ The allocation of meaningful, essential voting rights to contributors of an enterprise, for example, has led courts to hold that this prong is not met. ${ }^{165}$ Courts have considered the sophistication of investors ${ }^{166}$ and the ability to utilize their position to protect themselves ${ }^{167}$ as important factors in determining whether they are reliant on the promoter or third party. The amount of control over a DAPP's protocols withheld by a promoter will invariably affect this prong. ${ }^{168}$

\section{e. With a Focus on the Economic Reality of the Transaction}

Courts look to the commercial context and the terms of an offer in light of all the circumstances to determine whether Congress intended the Securities Act to cover the offering. ${ }^{169}$ Because U.S. securities laws are disclosure-based and not substance-based, it is insignificant whether there is a high risk of loss to an investment, so long as the market has adequate information. ${ }^{170}$ As the Howey Court put it, " $[\mathrm{I}] \mathrm{t}$ is immaterial whether the

162. Bamert v. Pulte Home Corp., 445 Fed. App’x 256, 262 (11th Cir. 2011) (quoting Williamson v. Tucker, 645 F.2d 404, 418 (5th Cir. 1981)).

163. Int'l Bhd. of Teamsters v. Daniel, 439 U.S. 551, 561 (1979); Glenn W. Turner Enters., 474 F.2d at 482-83; SEC v. Koscot Interplanetary, Inc., 497 F.2d 473, 483 (5th Cir. 1974); CoinBase, supra note 75 , at 17. Some courts, however, have maintained the original language of Howey, requiring a literal application of the word "solely". See Hirsch v. Dupont, 396 F. Supp. 1214, 1218 20 (S.D.N.Y. 1975), aff'd, 553 F.2d 750 (2d Cir. 1977).

164. See CoinBase, supra note 75, at 9-11.

165. Williamson v. Tucker, 645 F.2d 404, 421 (5th Cir. 1981); see also Klaers v. St. Peter, 942 F.2d 535, 536, 538 (8th Cir. 1991) (non-managing general partners retained eighty percent of voting rights, which was enough to allow them to exert control through the voting process).

166. Stewart v. Ragland, 934 F.2d 1033, 1038-40 (9th Cir. 1991) (non-operators of a well contracting agreement were sophisticated investors able to protect themselves).

167. Odom v. Slavik, 703 F.2d 212, 215 (6th Cir. 1983) (stressing the importance of leverage and ability of investors to protect themselves).

168. See Int'1 Bhd. of Teamsters v. Daniel, 439 U.S. 551, 562 (1979).

169. Landreth Timber Co. v. Landreth, 471 U.S. 681, 687 (1985).

170. SEC v. W.J. Howey Co., 328 U.S. 293, 301 (1946) ("We reject the suggestion of the Circuit ... that an investment contract is necessarily missing where the enterprise is not speculative or promotional in character and where the tangible interest which is sold has intrinsic value independent of the success of the enterprise as a whole."); see also SEC v. C. M. Joiner Leasing Corp., 320 U.S. 344, 352 (1943) ("It is urged that because the definition [of security] mentions 'fractional undivided interest in oil, gas or other mineral rights,' it excludes sales of leasehold subdivisions by parcels. Oil and gas rights posed a difficult problem to the legislative draftsman. Such rights were 
enterprise is speculative or non-speculative or whether there is a sale of property with or without intrinsic value."171

\section{f. And Disregarding Form for Substance}

Although potentially relevant, the terminology a promoter affixes to an offering is not dispositive as to its status as a security. ${ }^{172}$ Rather than the method, structure, or name in which an offering is made, courts focus on the characteristics of the offer itself and the circumstances of the offering. ${ }^{173}$ This focus on substance is essential to evaluating the offering against the spirit and intent of the Acts. ${ }^{174}$ In doing so, courts look at a purchaser's reasonable belief in what they are buying and whether the belief is based on the offered instrument itself and the actions of the promoter. ${ }^{175}$ If a person, trained or untrained, buying an instrument would expect it to be covered by securities laws (based on name and characteristics in context), then its purchase is likely to fall within the scope of the Act. ${ }^{176}$

Finally, just because an offering is attached to a larger scheme that involves securities or because similar-appearing offerings are securities, does not mean the instrument should itself be considered a security. As Justice Frankfurter said in his Howey dissent: "Simply because other arrangements may have the appearances of this transaction but are employed as an evasion of the Securities Act does not mean that the present contracts were evasive. I find nothing in the Securities Act to indicate that Congress meant to bring every innocent transaction within

notorious subjects of speculation and fraud, but leases and assignments were also indispensable instruments of legitimate oil exploration and production. To include leases and assignments by name might easily burden the oil industry by controls that were designed only for the traffic in securities.").

171. Id.

172. United Hous. Found., Inc. v. Forman, 421 U.S. 837, 850-51 (1975) ("In holding that the name given to an instrument is not dispositive, we do not suggest that the name is wholly irrelevant to the decision whether it is a security. There may be occasions when the use of a traditional name such as 'stocks' or 'bonds' will lead a purchaser justifiably to assume that the federal securities laws apply. This would clearly be the case when the underlying transaction embodies some of the significant characteristics typically associated with the named instrument."); Landreth, 471 U.S. at 690.

173. Howey, 328 U.S. at 301; Forman, 421 U.S. at 852.

174. Forman, 421 U.S. at 849 (citing Church of the Holy Trinity v. United States, 143 U.S. 457, 459 (1892)).

175. Id. at 851 ("Common sense suggests that people who intend to acquire only a residential apartment in a state-subsidized cooperative, for their personal use, are not likely to believe that in reality they are purchasing investment securities simply because the transaction is evidenced by something called a share of stock.").

176. Landreth, 471 U.S. at 693 (discussing how stock is the paradigmatic security that tempers the expectations of purchasers and is therefore clearly covered by the Acts). 
the scope of the Act simply because a perversion of them is covered by the Act." 177

\section{SEC Enforcement Actions}

This Section will provide some background on SEC action in the ICO space, highlighting the major developments of 2017 and early 2018 that represent the SECs first steps in regulating the industry.

\section{Release No. 81207 and the "DAO"}

On July 25, 2017, the SEC published its first major release regarding ICOs (the "Release"). ${ }^{178}$ SEC releases made pursuant to Section 21(a) of the Securities Exchange Act of 1934, such as the Release, are not formal adjudications of fact, but rather reports following an investigation of suspected misconduct. ${ }^{179}$ They are intended to provide information and guidance to the public and the courts ${ }^{180}$ and set out a regulatory roadmap. ${ }^{181}$ SEC investigative releases are not binding, but courts do give them deference, ${ }^{182}$ without relying on the SEC's findings or arguments. ${ }^{183}$ Given that ICOs and related technologies are cutting-edge and courts typically lag in their understanding of new technologies, ${ }^{184}$ courts may be inclined to give special deference to the SEC. Amidst a flurry of SEC

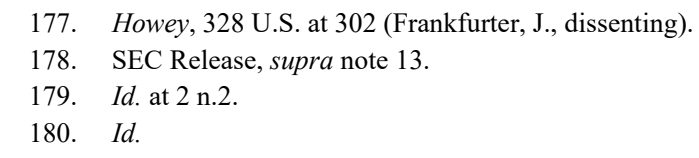

181. Margaret A. Dale \& Mark D. Harris, The SEC Concludes that Digital Tokens May Be Securities, N.Y.L.J. (Aug. 8, 2017, 2:04 PM), https://www.law.com/newyorklawjournal/almID/ 1202795025475/The-SEC-Concludes-That-Digital-Tokens-May-Be-Securities/?mcode $=1380566174$ $563 \&$ curindex $=14$ [https://perma.cc/PM5K-JKQU].

182. See Fed. Express Corp. v. Holowecki, 552 U.S. 389, 397 (2008) (“[W]e defer to an agency's reasonable interpretations of the statute when it issues regulations in the first instance. ..."); Trinity Wall St. v. Wal-Mart Stores, Inc., 792 F.3d 323, 337 n.9 (3d Cir. 2015) ("Each of the SEC's interpretive releases was adopted after notice and comment and thus merits our deference."); Dep't of Labor v. E. Associated Coal Corp., 54 F.3d 141, 147 (3d Cir. 1995) ("We accord greater deference to an administrative agency's interpretation of its own regulations than to its interpretation of a statute." (citations omitted) (emphasis added)); Amalgamated Clothing \& Textile Workers Union v. Wal-Mart Stores, Inc., 821 F. Supp. 877 (S.D.N.Y. 1993) (discussing precedential value of SEC letters).

183. Int'l Bhd. of Teamsters v. Daniel, 439 U.S. 551, 563, 566 (1979) ("Our own review of the record leads us to believe that this reliance on the SEC's interpretation of these legislative and administrative actions was not justified ... [T] here are limits, grounded in the language, purpose, and history of the particular statute, on how far an agency properly may go in its interpretative role. Although these limits are not always easy to discern, it is clear here that the SEC's position is neither longstanding nor even arguably within the outer limits of its authority to interpret these Acts.").

184. Gordon v. Dailey, No. 14-7495, 2016 U.S. Dist. LEXIS 80205, at *2, *5 (D.N.J. June 20, 2016) (wherein the court is unclear as to how to categorize Bitcoin). 
activity in the field, ${ }^{185}$ the purpose of the SEC's July 2017 Release was to put the blockchain community on notice that it intended to regulate the emerging industry. ${ }^{186}$ If the SEC plans to exert a lasting regulatory prerogative over ICOs, then it will need a court or the legislature to confirm the Commission's jurisdiction over the offerings it seeks enforcement against.

In the Release, the SEC condemned German company Slock.it after the company launched a popular ICO to fund an entity called the "DAO" ("Decentralized Autonomous Organization") but failed to comply with the Securities Act registration requirements. ${ }^{187}$ Although the SEC does not use the terminology, it essentially determined that the DAO ICO was the sale of tokenized securities, equating the sale to a public venture capital company fundraiser. ${ }^{188}$ The DAO ICO raised approximately $\$ 150$ million to be pooled and re-invested into other projects approved by a vote of token holders through the DAPP's protocols (subject to significant managerial control vested in a group of Slock.it-affiliated managers called "curators"). ${ }^{189}$ According to the SEC, the DAO tokens were tokenized securities rather than utility tokens because these insider curators had plenary authority over the deal pipeline. ${ }^{190}$ Additionally, the DAO investment voting system was structured in a way that discouraged authentic involvement by token holders, and promoters persistently advertised the tokens as an investment opportunity. ${ }^{191}$

Industry uncertainty following the release was palpable. Experts described the Release as anywhere from a "light regulatory touch," 192 to a "warning shot," 193 to a "crackdown"194 because of its ambiguity and

185. On July 25, 2017, the SEC also released an investor bulletin warning citizens of the riskiness of ICOs as well as a Statement by the Divisions of Corporation Finance and Enforcement encouraging participants to employ securities counsel. Investor Bulletin: Initial Coin Offerings, supra note 118; Statement by the Divisions of Corporation Finance and Enforcement on the Report of Investigation on The DAO, U.S. SEC. \& EXCH. COMM'N (July 25, 2017), https://www.sec.gov/news/publicstatement/corpfin-enforcement-statement-report-investigation-dao [https://perma.cc/8E9P-JE5Y].

186. Robert Khuzami et al., SEC Stakes Claim as Digital Currency Regulator, LAw360 (Oct. 13, 2017, 12:12 PM), https://www.law360.com/articles/974063/sec-stakes-claim-as-digital-currencyregulator [https://perma.cc/ZDT5-FX3W].

187. SEC Release, supra note 13.

188. See generally Robinson, supra note 7.

189. Id. at 3,7 .

190. See id. at 6-8.

191. Id. at 12 .

192. See Morgan, Hernand \& Tsai, supra note 76.

193. See Robert M. Crea et al., Legal Considerations After SEC's Warning Shot at ICOs, LAw360 (Aug. 21, 2017, 11:36 AM), https://www.law360.com/articles/955490/legal-considerations-after-secs-warning-shot-at-icos [https://perma.cc/7SQU-4GFR].

194. Katie Roof, SEC Regulators Are Coming After ICOs, TeChCRUNCH (July 25, 2017), 
factual focus. If nothing else, the Release foreshadowed the SEC's intent to pursue regulatory action in the future without providing much concrete guidance. ${ }^{195}$

This uncertainty, the prospect of regulation, and the specter of class action litigation ${ }^{196}$ have had a chilling effect in the crypto-industry, ${ }^{197}$ leading to the exclusion of many members of the American public from being able to invest in some major ICOs. ${ }^{198}$

https://techcrunch.com/2017/07/25/sec-regulators-are-coming-after-icos/ [https://perma.cc/E4V4Q8JJ]; Joon Ian Wong, The SEC Is Cracking Down on Small-Time "Initial Coin Offerings," But the Mega ICOs Are Here to Stay (Oct. 2, 2017), https://qz.com/1091812/the-secs-ico-crackdown-may-beavoided-by-the-saft-legal-framework/ [https://perma.cc/J6AX-9ECK]; see also Paul Anderson \& Harriet Rogers, Initial Coin Offerings May Face A Global Crackdown, LAw360 (Nov. 21, 2017, 11:43 AM), https://www.law360.com/articles/987282/initial-coin-offerings-may-face-a-global-crackdown [https://perma.cc/A73Y-YFRJ].

195. Jeffrey Alberts \& Yvonne Saadi, The SEC Is Watching Cryptocurrencies, So Beware-But Don 't Overreact, NASDAQ (Oct. 4, 2017, 5:47 PM), https://www.nasdaq.com/article/op-ed-the-sec-iswatching-cryptocurrencies-so-beware-but-dont-overreact-cm855458; see also Pesok \& Brylski, supra note 21; Adam T. Ettinger, The SEC and ICOs: Putting the SEC's Determination that DAO Tokens Are Securities in Context, NAT'L L. REV. (July 27, 2017), https://www.natlawreview.com/article/secand-icos-putting-sec-s-determination-dao-tokens-are-securities-context [https://perma.cc/H7RVV7VX].

196. Such as a November 2017 lawsuit against crypto-ledger startup Tezos, which raised $\$ 232$ million through its ICO. See generally L.M GOODMAN, TEZOS-A SELF-AMENDING CRYPTO-LEDGER WHITE PAPER (2014), https://www.tezos.com/static/papers/white_paper.pdf [https://perma.cc/ MSM5-UA6U]; Anna Irrera \& Steve Stecklow, Tezos Organizers Hit with Second Lawsuit Over Cryptocurrency Fundraiser, REUTERS (Nov. 15, 2017, 4:58 PM), https://www.reuters.com/article/usbitcoin-tezos/tezos-organizers-hit-with-second-lawsuit-over-cryptocurrency-fundraiseridUSKBN1DF37L [https://perma.cc/XR68-MY8F].

197. See, e.g., Smith, supra note 79 ("The SEC's stance may scare many new ICO's away ... ."); Dale \& Harris, supra note 181 ("[I]t is likely the SEC's involvement will cause some initial chilling effects, specifically as a result of requiring exchanges to register as securities exchanges and comply with the associated requirements.").

198. Andrew Ramonas, No U.S. Investors Need Apply for Some Digital Coin Offerings, BLOOMBERG BNA (Aug. 31, 2017), https://www.bna.com/no-us-investors-n73014463997/ [https://perma.cc/7FCG-L9LV]. This is not a phenomenon exclusive to America. Canada, which has taken a similar stance to the U.S., saw Canadian investors excluded from token sales by a Canadian giant, Kik Interactive, Inc., due to regulatory uncertainty. Gerrit De Vynck, Kik Blames Canadian Regulators for Skipping Country in ICO, BLOOMBERG (Sep. 7, 2017, 5:01 PM), https://www.bloomberg.com/news/articles/2017-09-07/kik-blames-canadian-regulators-for-skippingcountry-in-ico ("Chief Executive Officer Ted Livingston blamed 'weak guidance' from the Ontario Securities Commission for the decision."); Alexandria Posadzki, Canadian Cryptocurrency Advocates Push for More Leniency on Initial Coin Offerings, THE Globe \& MAIL (Oct. 9, 2017), https://www.theglobeandmail.com/report-on-business/canadian-cryptocurrency-advocates-push-formore-leniency-on-initial-coin-offerings/article36526808/ [https://perma.cc/V9RS-MHKN]. China's recent cryptocurrency ban has driven their innovators to Japan, Singapore, and Hong Kong. China's Cryptocurrency Barons Seek New Life in Japan, HK, THE BUS. TIMES SingAPORE (Oct. 28, 2017, 5:50 AM), https://www.businesstimes.com.sg/life-culture/chinas-cryptocurrency-barons-seek-newlife-in-japan-hk [https://perma.cc/7W5X-TVMG]. 


\section{Munchee's Cease-and-Desist Order \& Settlement}

In December 2017, the SEC sent a Cease-and-Desist Order to Munchee, Inc., a California restaurant-review-app-company, after the $\$ 15$ million ICO of a purported utility token. ${ }^{199}$ Considering the tokens sold by Munchee (called MUN) had real utility, this came as a shock to many in the ICO community who believed such tokens were beyond the purview of the SEC. ${ }^{200}$

MUN tokens were both given to users for writing restaurant reviews (which they could use to redeem discounts at partner restaurants) and sold to restaurants that would use the tokens to pay for advertising on the platform. $^{201}$ This sounds like a quintessential utility token, but in the context of the MUN "ecosystem" it was not so-at least in the view of the SEC. Munchee hoped more users would be attracted to use the DAPP because of the helpful reviews and the value of the MUN tokens would appreciate due to their increasing demand and limited supply (in fact, a diminishing number due to a "burn" policy). ${ }^{202}$ After this value increase, MUN holders could sell their MUN on secondary exchanges for a profit. Munchee went as far as to guarantee a resale market and lauded MUN's projected appreciation in their promotional materials. ${ }^{203}$

According to the SEC Order, MUN token sales were unregistered investment contracts because MUN purchasers expected their profits to arise from continued DAPP development, cultivation of Munchee's ecosystem (incentive structure), ${ }^{204}$ and Munchee's promoters playing a major role in the application for at least several years per their product roadmap. ${ }^{205}$

The Order stands for the proposition that calling a token a "utility token" and having a use-case native to the DAPP does not absolve it from

199. Munchee Inc., Exchange Act Release No. 10445 (Dec. 11, 2017) [hereinafter Munchee Order], https://www.sec.gov/litigation/admin/2017/33-10445.pdf [https://perma.cc/JV3D-73YD] (instituting cease-and-desist proceedings pursuant to Section 8A of the Securities Act of 1933, making findings, and imposing a cease-and-desist order).

200. See, e.g., Andrew D. Ledbetter \& Trenton C. Dykes, SEC Eats Away at Munchee "Utility Tokens": Guidance for ICOs, DLA PIPER PUBLICATIONS (Dec. 14, 2017), https://www.dlapiper.com/ en/us/insights/publications/2017/12/sec-eats-away-at-munchee-utility-tokens-guidance-for-icos/ [https://perma.cc/7Z54-Q6T7]; Budofsky \& Robbins, supra note 25.

201. Munchee Order, supra note 199, at 1.

202. Id. at 5 .

203. Id.

204. See, e.g., James G. Gatto, SEC Takes \$15 Million Bite Out of an ICO, NAT’L L. REv. (Dec. 12, 2017), https://www.natlawreview.com/article/sec-takes-15-million-bite-out-ico [https://perma.cc/ QN4P-X8TK].

205. Munchee Order, supra note 199, at 4-5. 
registration in the SEC's eyes, ${ }^{206}$ and that the SEC intends to make strong moves in the utility token space. ${ }^{207}$ The Order also stands for the proposition that the SEC is perhaps more concerned with the marketing surrounding ICOs, rather than the substance of the ICO itself. For example, the SEC emphasized the fact that the Munchee application would only be available in the United States, yet MUN tokens were marketed and sold across the world, plus the fact that Munchee released promotional material aimed at crypto-speculators essentially guaranteeing returns. ${ }^{208}$ Despite Munchee clearly disclaiming in its ICO white paper that MUN tokens were not a passive investment, their actions clearly betrayed their words. ${ }^{209}$

\section{SEC Chair Statement and Regulatory Mindset}

On December 11, 2017 SEC Chairman Jay Clayton released a public statement on cryptocurrencies and ICOs, mainly concerned with providing considerations for "Main Street Investors." 110 Most interestingly, before stating that "the structures of [all] initial coin offerings that I have seen promoted involve the offer and sale of securities," Clayton gave an example of an ICO that might not be a security. ${ }^{211}$ Clayton stated that in addition to marketing materials, the SEC is concerned with the developmental stage of projects:

For example, a token that represents a participation interest in a book-ofthe-month club may not implicate our securities laws, and may well be an efficient way for the club's operators to fund the future acquisition of books and facilitate the distribution of those books to token holders.

\footnotetext{
206. Id. at 9-10.

207. See, e.g., Ledbetter \& Dykes, supra note 200.

208. Munchee Order, supra note 199, at 6 ("Munchee and its agents targeted the marketing of the MUN tokens offering to people with an interest in tokens or other digital assets that have in recent years created profits for early investors in ICOs. This marketing did not use the Munchee App or otherwise specifically target current users of the Munchee App to promote how purchasing MUN tokens might let them qualify for higher tiers and bigger payments on future reviews.").

209. Sanjeev Verma, Nghi Bui \& Chelsea Lam, Munchee Token: A Decentralized Blockchain Based Food Review/Rating Social Media Platform, 2-4 (updated Oct. 16, 2017), https://www.theventurealley.com/wp-content/uploads/sites/5/2017/12/Munchee-White-Paper.pdf [https://perma.cc/N6T9-FHU9] ("Readers are cautioned not to place undue reliance on these forwardlooking statements in making any personal decision.... Participation in a token sale can be highly speculative and could involve a risk of loss. This White Paper does not constitute the offering of a security.").

210. Statement on Cryptocurrencies and Initial Coin Offerings, U.S. SEC. \& Exch. Comm'N (Dec. 11, 2017), https://www.sec.gov/news/public-statement/statement-clayton-2017-12-11 [https://perma.cc/47DP-ZR97].
}

211. Id. 
In contrast, many token offerings appear to have gone beyond this construct and are more analogous to interests in a yet-to-be-built publishing house with the authors, books and distribution networks all to come. $^{212}$

Clayton ends his statement with a reassurance that the SEC will continue to "vigorously" assert itself in the ICO space. ${ }^{213}$

Although neither binding law nor adjudication of fact, Chairman Clayton's statement distills his, and therefore the SECs, stance on ICOs. The agency sees the technology's promise overshadowed by manic speculation and deception in the market. ${ }^{214}$

\section{ANALYSIS}

This Part will argue that DAPP utility tokens should not be considered securities. First, it will describe the difficulties of applying Howey to utility tokens and why analysis of utility tokens should yield a result favorable to an honest, non-manipulative ICO promoter. Then, this Part will provide policy reasons why courts should not categorize most utility tokens as securities. Finally, this Part briefly describes alternative means to regulate ICO-mania other than through securities registration.

\section{A. Applying Howey to Utility Tokens}

In its DAO and Munchee releases the SEC analyzed Howey. ${ }^{215}$ In both instances, the SEC determined the examined tokens were securities without explicitly describing them as either equity tokens or utility tokens, although Munchee explicitly claimed its MUN was a utility token. ${ }^{216}$ However, in the absence of misleading marketing efforts, such as "guaranteeing" returns, utility tokens sales should not be considered investment contracts, as this Part endeavors to support.

\footnotetext{
212. Id.

213. Id.

214. See Josiah Wilmoth, Your Utility Token ICO Is Probably a Securities Offering: SEC Chairman, CCN (Dec. 13, 2017), https://www.ccn.com/utility-token-ico-probably-securitiesoffering-sec-chairman/ [https://perma.cc/8S3E-MCJD]; Alex Hern, Bitcoin Buyer Beware: US SEC Warns 'Extreme Caution' over Cryptocurrency Investments, THE GUARDIAN (Dec. 12, 2017, 6:25 AM), https://www.theguardian.com/technology/2017/dec/12/bitcoin-buyer-beware-us-sec-warnsextreme-caution-over-cryptocurrency-investments [https://perma.cc/DE2F-3JPD].

215. Munchee Order, supra note 199, at 8.

216. Verma, Bui \& Lam, supra note 209, at 3.
} 


\section{Factual Intensity \& Jurisdictional Issues}

The litigation-intensive process of Howey application may be impractical in a rapidly-developing, global, and online front. The amount of controversy and disagreement as to the applicability of Howey to ICOs may indicate that Howey is an antiquated and inadequate framework for handling these issues. ${ }^{217}$

\section{a. Application of Howey is Necessarily a Factually Intense Question}

Because courts will likely examine each Howey claim anew under each unique set of facts, it is inherently a time-and-resource-consuming task for the court, regulators, and issuers alike to adjudicate in each instance. ${ }^{218}$ The court is required to look beyond the form of the token and its sale to divine its essence. ${ }^{219}$ Although ICOs may be structurally similar, each token may provide radically diverse rights and functionality to their holders, arising under different contexts, and therefore the court must endeavor to understand these unique features. These features include, but certainly are not limited to: access and use rights, license rights, labor contribution compensation, non-money computing power contributions, re-sale rights, franchise rights, many varieties of voting rights, ownership interests in the entity, equity interest in the application, profit sharing, loss liability, sharing of assets, claims in bankruptcy, debt obligations, control of source code, vesting requirements, and convertibility. ${ }^{220}$ An adjudicator must understand how these rights and interests apply to holders of particular tokens, how they interplay and counterbalance, whether they are meaningful or trivial, durable or fleeting, promised or delivered, and ultimately must draw fine (and squiggly) lines between tokens that primarily represent equity with those that represent utility. Adjudicators must also attempt to understand who was transacting, why they transacted, what their expectations were, at what point in the application development

217. See, e.g., Robinson, supra note 7, at 52-53.

218. Gertrude Chavez-Dreyfuss, U.S. SEC Official Urges Companies Issuing Tokens to Protect Investors, REUTERS (May 23, 2017), https://www.reuters.com/article/us-sec-blockchain/u-s-secofficial-urges-companies-issuing-tokens-to-protect-investors-idUSKBN18K05Q [https://perma.cc/ $\mathrm{X} 7 \mathrm{LN}-9$ W2H] (quoting Valerie Szczepanik, "Whether a token is a security or not is a fact or circumstance-based thing and you have to really pick it apart."). Szczepanik is the leader of the SEC's distributed ledger working group, and as of June 2018, Senior Advisor for Digital Assets and Innovation. See SEC Names Valerie A. Szczepanik Senior Advisor for Digital Assets and Innovation, U.S. SEC. \& EXCH. COMM'N (June 4, 2018), https://www.sec.gov/news/press-release/2018-102 [https://perma.cc/6L6R-C745].

219. SEC v. W.J. Howey Co., 328 U.S. 293, 298 (1946).

220. CoinBase, supra note 75 , at 10. 
stage was the token issued, what was the ongoing involvement of the issuer, what representations did they make and what are their implications, how sophisticated was the investor, and more.

Given that technology, particularly in the blockchain space, develops much quicker than does jurisprudence, the courts may find themselves assigned a novel, nuanced " 21 st century problem with 18 th century tools." 221 Courts and startups alike are ill-equipped, underfunded, and generally too busy for these kinds of fact-intensive disputes. Although Howey's definition of investment contract embodies a "flexible rather than a static principle, one that is capable of adaptation to meet the countless and variable schemes devised ...", 222 it is much easier said than applied.

Given the sheer number of permutations of rights and interests associated with tokens, particularly tokens with utility, regulatory certainty will be hard to come by-unless courts make sweeping judgments regarding these technologies, which may be more disruptive than helpful. ${ }^{223}$ Lingering regulatory uncertainty "attending the applicability of the Acts would hardly be in the best interests of either party to a transaction." 224 This uncertainty will be inevitable unless the pendulum swings back past the SEC and courts or legislatures create carve-outs for some ICOs from the securities laws.

b. There will Almost Always be Jurisdictional Issues

Certain features of blockchain applications present difficult jurisdictional questions that must be tackled in most adjudications. ${ }^{225}$ The pseudonymity of which many blockchain participants and crypto-asset users transact with makes tracking them down and verifying their identity problematic. $^{226}$ The globally distributed, liquid networks and start-up teams that constitute and create blockchains may make it impractical to

221. Federico Ast \& Clément Lesaege, Kleros: Fighting Scams and Abuse in Token Sales, MEDIUM (Nov. 27, 2017), https://medium.com/kleros/kleros-a-tool-against-abuse-in-tokendistribution-924217746c16 [https://perma.cc/QZ9E-FFGV].

222. Howey, 328 U.S. at 299.

223. Landreth Timber Co. v. Landreth, 471 U.S. 681, 699-700 (1985) (Stevens, J., dissenting) ("Nevertheless, I am persuaded that the interests in certainty and predictability that are associated with a simple 'bright-line' rule are not strong enough to 'justify expanding liability to reach substantive evils far outside the scope of the legislature's concern."' (emphasis added)).

224. Id. at 696.

225. See, e.g., Robinson, supra note 7, at 52-53.

226. Ast \& Lesaege, supra note 221 ("Jurisdictional boundaries don't play well with a practice where thousands of participants from dozens of countries enter into a contract with a startup team which is also distributed around the world. The decentralized global economy requires a global and decentralized institutional framework native to the Internet Age."). 
locate a principal place of business or establish exactly where transactions are taking place. $^{227}$ When smart contracts allow applications and organizations to run autonomously, it becomes difficult to determine who is responsible for causing what to happen-is it the coders who launch the applications, or those who trigger occurrences down the road? These issues, and more, will present themselves in any enforcement action.

\section{Howey and Expectations}

ICOs almost certainly involve the investment of money, and analysis of such is beyond the scope of this Comment. Whether token holders are in a common enterprise with each other or with the ICO promoters is a cloudier question, but also beyond this Comment's focus. This Section instead focuses on the expectations of token buyers, the third discussed prong of the Howey test.

a. Reasonable utility token holders do not have the same expectations as passive investors

If a utility token holder expects that her actions can improve number or value of her tokens, then she is incentivized to engage with or promote the application on which she is a stakeholder. Although, like in many aspects of the economy, the specter of free riding exists, her best strategy for maximizing token value involves using it (or at least relies on the implicit assumption that the token will have use to her or others in the future). Understanding this, a reasonable participant, one who at least marginally understands the technology and model before investing, will be motivated by the usefulness of the tokens for commercial or personal use. When the typical purchaser is attracted solely by the promise of potential financial returns, the instrument looks like a security; but when the purchaser intends to use, consume, or occupy the instrument, then securities laws should not apply. ${ }^{228}$ In examining stocks that allowed the purchaser to live in a democratically owned and controlled housing cooperative, the Court in United Housing Foundation v. Forman held that

227. See Megan Stumph-Turner, Bitcoin, Bankers, and Barriers to Legislation, BAKER, STERCHI, COWden \& Rice LlC Financial Services LaW Blog (Dec. 4, 2017), http://www.bscrlaw.com/?t=40\&an=72169\&format $=x m l \&$ stylesheet=blog $\& \mathrm{p}=5258$ [https://perma.cc/64P7-R8M9].

228. United Hous. Found., Inc. v. Forman, 421 U.S. 837, 852-53 (1975) ("In such cases the investor is 'attracted solely by the prospects of a return' on his investment. By contrast, when a purchaser is motivated by a desire to use or consume the item purchased - 'to occupy the land or to develop it themselves,' as the Howey Court put it, the securities laws do not apply." (citations omitted)). 
despite potential economic interest in appreciation at resale, the purchase of stock was to secure a commodity for personal use and therefore not a security. ${ }^{229}$

The information in and framing of the offer in promotional materials will surely affect expectations of purchasers. ${ }^{230}$ In Forman, the investment materials sought to attract stock purchasers by heralding the benefits of the housing cooperative to residents rather than profits from the investment, which favored the determination that the stock was not a security. ${ }^{231}$ Slock.it's DAO, on the contrary, advertised itself as an investment vehicle, and therefore purchasers expected relatively passive income - at most they would have to vote on pooled investment proposals. ${ }^{232}$ Additionally, when Munchee heavily marketed and sold MUN overseas (where there were no partner restaurants), it should have been prima facie evidence that those purchasers could not have been buying with consumptive intent. If a blockchain application token has true utility, however, then that utility will (or should) certainly be emphasized by the promoters in marketing materials and white paper. It also seems clear that if a white paper has a clear legal disclaimer pointing out that the consumer should not expect SEC intervention, then we should construct their expectations to reflect that.

Finally, the SEC seems to assume that investors in ICOs are representative of the U.S. investor population at large. However, tokens are not available on consumer platforms like E*TRADE-consumers must have a special level of sophistication to access ICOs and a higher risk tolerance to buy into DAPPs that rely on network effects and typically have no physical assets as collateral. In determining whether a housing cooperative's stock was a security in Forman, Justice Powell pointed to the common-sense beliefs of the stock purchasers and whether the characteristics of that stock "in our commercial world fall within the ordinary concept of a security." ${ }^{233}$ Courts should situate their analysis in the commercial context in which the transactions occur: here, the market for blockchain application tokens. The ICO market is a market where relatively sophisticated, risk-tolerant parties expect to get utility from utility tokens and do not expect government oversight of the processespecially when white papers explicitly warn of the lack of securities protections, like Munchee's did. ${ }^{234}$

\footnotetext{
229. Id. at 858.

230. See id. at $852-53$.

231. See id. at $853-54$.

232. See generally SEC Release, supra note 13, at 6-8.

233. Forman, 421 U.S. at 851 (citations omitted).

234. Cf., Robinson, supra note 7; Munchee Order, supra note 199.
} 
b. The Value of Utility Tokens Relies on the Activities of Users

The SEC's Munchee cease-and-desist order does not support the idea that where a DAPP relies on the network of users itself to create value, then the efforts of the token holders themselves are undeniably essentialthough it should. The SEC argues that the Munchee ecosystem's designed requirement that its users transact in MUN tokens was not essential enough to circumvent Howey. However, where an ICO's marketing and structure is less focused on pure token-value appreciation and more on the existence of a robust DAPP ecosystem, it shows that the undeniably essential efforts are those of the participants. This is especially true when a postdevelopment DAPP is operated by smart contracts (as opposed to promoters).

An analysis of a genuine utility token ${ }^{235}$ shows that token holders, buying into what is essentially an incentive structure, reasonably expect primarily to benefit, financially, commercially, or personally, from their own actions and the collective actions of other token holders, not the promoters. With Filecoin, for example, token holders expect to be able to use their tokens to purchase storage from another participant's excess digital storage capacity. ${ }^{236}$ Alternatively, when the participant provides her excess storage, she expects to receive tokens in return. Both parties, and the network itself, are enriched by mutual participation. Supplemental cyber security audits and promotional activities by the issuers are more like incidental services (of which they are rewarded by retaining or earning their own tokens) rather than the activities that create value for token holders. ${ }^{237}$ The fact that issuers make the market and add some value should not make an instrument a security if the majority of the value of the enterprise (or at least a necessary amount) comes from the active participation of the instrument holders. ${ }^{238}$

\footnotetext{
235. See supra Section II.A.3(b).

236. Filecoin, supra note 95.

237. This Comment generally ignores the hornet's nest created by the different development stages at which the creators of a DAPP chose to conduct an ICO. For the sake of argument, I assume that most ICOs are occurring after the intellectual heavy-lifting of conceptualizing the ecosystem in a white paper and writing serviceable code. Clearly, if a promoter conducts an ICO pre-white paper or pre-product, the endeavor is more speculative and the opportunity for abuse even more acute.

238. Int'l Bhd. of Teamsters v. Daniel, 439 U.S. 551, 562 (1979) ("In the case of a pension fund, however, a far larger portion of its income comes from employer contributions, a source in no way dependent on the efforts of the Fund's managers. The Local 705 Fund, for example, earned a total of $\$ 31$ million through investment of its assets... [whereas] employer contributions totaled $\$ 153$ million. Not only does the greater share of a pension plan's income ordinarily come from new contributions, but unlike most entrepreneurs who manage other people's money, a plan usually can count on increased employer contributions, over which the plan itself has no control, to cover shortfalls
} 
Further, appreciation of the token on secondary markets as the application's usefulness is proved should not be attributed solely to the promoters, but to the mutually beneficial behaviors of the token holders and the network effects they bring. Bitcoin, for a prolific example, only has value as a currency because its users transact with it, and its value as a currency increases as more people decide to recognize its validity.

\section{Focusing on Economic Realities and Placing Substance over Form}

As the SEC points out in its release, "form should be disregarded for substance," 239 "and the emphasis should be . . . on the economic realities underlying a transaction ...." 240 This means that making categorical determinations as to the applicability of securities laws on the basis of the token sale's occurrence is improper, absent policy contravention or carveout to the contrary. Thus far, the SEC has seemed more focused on the (oftentimes opportunistic) marketing efforts and external hype surrounding an ICO itself, rather than the substance offered in the DAPP. Impropriety in the industry does not diminish the right of each ICO to be individually judged. To lump ICOs together and constructively presume they are securities would be to focus on the form of the offering rather than the substance - to focus on the vehicle itself as opposed to the instrument it contains. To refuse the existence of legitimate, non-security utility tokens would be to throw the baby out with the bathwater, or as Justice Frankfurter put it, "bring every innocent transaction within the scope of the Act simply because a perversion of them is covered by the Act." ${ }^{241}$ As discussed throughout this analysis, the economic reality of utility tokens does not lend itself to classification as an investment contract nor do the commercial participants expect it. As the technology progresses and developers create better DAPPs that run on better smart contracts with less human intervention, our economic reality shifts as DAPPs get further away from our general conceptions of business organizations. Ultimately, if the code and the crowd primarily run a DAPP ecosystem, then the undeniable economic reality is that securities laws do not make sense to apply.

Finally, in Howey, which analyzed the sale of securitized citrus groves, there was no right of instrument holders to a specific fruit in the grove nor did they have a general right of entry on the groves - the produce

in earnings.").

239. SEC Release, supra note 13, at 11 (citing Tcherepnin v. Knight, 389 U.S. 332, 336 (1967)).

240. SEC Release, supra note 13, at 11 (citing United Hous. Found., Inc. v. Forman, 421 U.S. 837, 848-49 (1975)).

241. SEC v. W.J. Howey Co., 328 U.S. 293, 302 (1946) (Frankfurter, J., dissenting). 
was farmed, pooled, and sold by the company, then profits were distributed. ${ }^{242}$ With tokens, the holder has a right to the specific token they purchased, which is protected by cryptography and accessible only with the holder's private key, which gives them the exclusive right to access and use the token; far from an abstract indicia of a right to profit.

Although tokens are intangible and sometimes heralded as investments, courts look past form and instead focus on the substance of the transaction: utility token sales are the sales of valuable property, as described in Section III.B.1.

\section{B. Policy Arguments against Sweeping Securities Regulations of Utility Tokens}

Courts should not strain themselves to bring utility tokens within the purview of the Securities Act. The treatment of utility token sales as securities runs counter to public policy and is largely unnecessary to achieve the legislative goals of consumer protection and capital formation.

\section{Exclusion of the U.S. Market from ICOs}

Regulation of ICOs is a uniquely global problem because offerings are made by teams whose members are distributed around the globe. ${ }^{243}$ The government taking a hardline stance on crypto-assets and ICOs will lead to the exclusion of its constituents from the fledgling industry and expatriation of entrepreneurs to friendlier jurisdictions. ${ }^{244}$

\section{a. Exclusion of U.S. Investors}

One of the most exciting aspects of token sales is that they provide the opportunity for more citizens to get involved in entrepreneurial finance, an area long dominated by venture capitalists and institutional investors. ${ }^{245}$

\footnotetext{
242. Id. at 296 .

243. See, e.g., Justina Lee, China Ban Can't Solve Legal Puzzle of Cryptocurrency Sales, BLOOMBERG (Sept. 5, 2017), https://www.bloombergquint.com/china/2017/09/05/china-ico-banflattens-issue-of-how-to-regulate-cryptocurrencies [https://perma.cc/ZKS5-DBNC] ("As regulators show increased interest in ICOs, some sales have started to exclude investors in certain jurisdictions such as the U.S.").

244. See, e.g., Robinson, supra note 7, at 51 ("As is true with any insertion of governmental regulation, those adverse to the costs of compliance will move from locations where that cost is high to locations with lower regulatory compliance costs.").

245. Brownell, supra note 10 (Proponents say ICOs give ordinary people an opportunity to invest in new blockchain technologies that will drive change on a comparable scale to that brought about by the internet).
} 
Not only does this democratize which projects accumulate capital, but utility tokens sales also allow the non-wealthy to be co-creators in the ecosystem and participate in an exciting new model that could change the way the Internet is used and businesses are formed.

However, if the United States stringently imposes securities regulations, issuers will just sell their tokens in foreign markets with lesser risk of legal liability. Canada, for example, has taken a similar approach to the SEC, and unfortunately, has yielded this result. ${ }^{246}$ For example, Kik Interactive Inc., a large Canadian online messaging company, did not open its one hundred-million-dollar token sale to Canadian citizens because of regulatory uncertainty from the Canadian securities watchdogs. ${ }^{247}$

In selling to U.S. residents, ICO issuers may circumvent some federal securities laws by registering for a Regulation D private-placement-foraccredited-investors exemption. By imposing securities regulations, but opening the door for wealthy accredited investors, the government further drives a stake between economic classes and deprives a social stratum from the ability to participate in the new economy.

\section{b. Exclusion of U.S. Issuers}

Blockchain entrepreneurs are not a captive audience. They form flexible, international teams who can move at the drop of a hat because their work is software based and not tied to physical capital investments. ${ }^{248}$ In the new economy, business is mobile. Coders can just as easily facilitate work online from across the globe. China, for example, has taken an extreme route in banning cryptocurrency and ICOs outright and has seen its tech innovators flee to places like Japan, which has the world's most robust crypto-market. ${ }^{249}$

2. Self-Regulation May be More Effective at Protecting the Public

If the purpose of the SEC is to protect investors, maintain efficient

\footnotetext{
246. Lee, supra note 243.

247. Shecter, supra note 22 ("Kik Interactive Inc. raised more than $\$ 100$-million from a token offering in September, but Canadians were left out of the action after its backers cited uncertainty over whether securities laws would apply to the offering.").

248. See generally Morgan, Hernand \& Tsai, supra note 76; Penina Finger, Fluid Teams: The Way You'll Work for the Rest of Your Career, WeB DESIGNER DePOT (June 5, 2014), https://www.webdesignerdepot.com/2014/06/fluid-teams-the-way-youll-work-for-the-rest-of-yourcareer/ [https://perma.cc/PC6G-W2ZY].

249. Lee, supra note 243. China likely did this in the interest of a strong yuan given the threat
} that cryptocurrencies pose to national fiat currencies. 
markets, and facilitate capital formation, its interest may be better served if it chose not to seek full securities law application to utility tokens, but instead embraced a novel regulatory scheme that bolsters innovation rather than hamstringing it. ${ }^{250}$

a. Securities Registration of Utility Tokens is Unnecessary and Insufficient

Imposing registration and compliance requirements on utility token issuances may hamper genuine innovators without effectively screening the opportunists. The intent of securities regulations generally may be to separate wheat from chaff in instrument sales, but here it may instead separate the well-lawyered from the bootstrapped, as hiring securities lawyers is costly and developers are (at least in part) using ICOs because traditional venture capital funding is hard to come by.

Securities regulations may also, in a sense, be under-inclusive. It is not apparent that the creation of a prospectus would help the average person better understand the token sale than would the white paper. One must concede, however, that SEC compliance could add legitimacy to an ICO and the protections it provides may be a value-add for token buyers. ${ }^{251}$ Some ICO issuers have stressed their voluntary legal compliance efforts as a differentiator in their marketing materials. ${ }^{252}$ Proponents may further argue that registration benefits issuers and purchasers because of the existing well-developed case law that clearly sets forth rights, obligations, and protections of the transacting parties. ${ }^{253}$ Perhaps regulators are right and the registration process will weed out only disingenuous or fraudulent issuers, but this is a risky proposition in a fluid, global industry founded on a libertarian and anarcho-communitarian ethos.

As for investor protection, with all the warnings, news of hacks, dooms-day dot-com Bitcoin-bubble prognostication in the media, it is hard to say that buyers do not understand the risk in the market. The real outcomes of the regulations seem to bubble-wrap people without considering the context surrounding the novel instrument. If regulation funnels investment opportunities only to accredited or overseas investors, then average citizens cannot harm themselves, so it seems.

\footnotetext{
250. See Robinson, supra note 7, at 54-56; accord Brownell, supra note 10.

251. Benoliel, supra note 79.

252. Brownell, supra note 10 ("Impak Finance, a Montreal-based ethical investing cryptocurrency, has decided to take things a step further in terms of regulation and trust. The company was the first to obtain approval to sell and manage a security from all 10 Canadian provinces before launching its ICO in August.").

253. Why ICOs Should Want to Be Securities, supra note 101.
} 
b. The Private Sector is Making Strides to Protect the Public

As ICOs have proliferated, so have private efforts at self-regulation. ICO watchdogs, trustworthiness rating agencies, countless consultants, financial intermediaries, ${ }^{254}$ databases and more have sprung up to hold ICO issuers accountable, fact-check, and provide information to consumers. ${ }^{255}$

Consumer protection devices can also be built directly into the code of the application. For example, programmers can set protocols so that funds raised through ICOs are essentially held in escrow until the development team reaches milestones or other smart contract-triggering activities, combating the perverse incentive of pump-and-dump fundraising. ${ }^{256}$ Additionally, there is industry mobilization for selfgovernance. The ICO Governance Foundation, for example, is facilitating voluntary ICO disclosure documents - the private equivalent to the SEC's EDGAR database. ${ }^{257}$

The more trust that those in the industry can cultivate in the public, the more freely capital will flow to ICOs and the more valuable their projects will be, so repeat-players are incentivized to behave fairly. ${ }^{258}$ The entrepreneurial spirit is engrained in the American conscience, and we should allow this experiment in private regulation to take place to encourage such innovation.

\section{c. Regulation of Blockchain Applications is Counterintuitive}

Regulation may be mutually exclusive to a truly functional, autonomous blockchain application created by pseudonymous issuers and governed by smart contracts. Section 5 of the Securities Act, for instance, requires inclusion of the identity and background of management in the statutory prospectus. ${ }^{259}$ Pseudonymous actors and believers in selfsovereign identity, such as Bitcoin creator "Satoshi Nakamoto" may be reluctant to comply with such a requirement. Not only is regulation of an

254. Thoughts on the SAFT, PRESTON BYRNE (Aug. 4, 2017), https://prestonbyrne.com/ 2017/08/04/thoughts-on-the-saft/ [https://perma.cc/DA8V-8K5J]. The SAFT (Simple Agreement for Future Tokens) is a financial invention to circumscribe securities regulations and provide protection to token-buyers based on tech incubator Y Combinator's SAFE (Simple Agreement for Future Equity).

255. See Science Inc. Launches Financial Information Service ICO Watchdog, MEDIUM (Oct. 24,

2017), https://medium.com/@scienceinc/science-inc-launches-financial-information-service-icowatchdog-d08d448e92ba [https://perma.cc/HM5L-AXEX].

256. Ast \& Lesaege, supra note 221.

257. Brownell, supra note 10.

258. Id.

259. SEC Release, supra note 13, at 10. 
immutable, virtual, global, and autonomous system a logistical nightmare, nationalized regulation runs anathema to the ethic of the technology and may serve to hamper startups and tech adventurers from exploring aspirational technology.

\section{Suggested Regulatory Treatment for Utility Tokens}

Impropriety in the ICO space primarily comes in the form of fraud, mania-manipulation, and hacking - all of which have consumer protection remedies outside of punishments for failure to register as a security offering. For example, when an ICO issuer fraudulently claims to have diamond reserves or a fully developed product or guarantees returns, and they in fact do not, buyers can still recover (under theories of tort, contract, and criminal law) if we look at them as purchasers of an asset rather than investors or speculators. When a hack occurs and token-holders lose their tokens, it is not the fault of the ICO promoter, but the criminal cyber-thief (although remedying this theft is difficult as well). Robust and innovative consumer protections for token holders should be explored before turning to an ill-equipped, controversial, and risky application of securities laws rooted in the precautionary principle. ${ }^{260}$

\section{Govern as the Sale of Fungible Assets or Commodities}

Depending on the level of risk involved, true utility tokens operate more like gift cards (or poker chips) than stocks or loans. Even if utility tokens potentially appreciate, their essence is to grant access to the platform's features and should be viewed as the crowd-sale of an asset. ${ }^{261}$

The speculative nature of crypto-assets is giving rise to markets for options and futures (at least in Bitcoin, for now). That is, many financiers are treating crypto-assets as commodities. Commodities are vital goods that can be anything people speculate on (except onions by legislative decree) ${ }^{262}$ but are usually thought of as fungible assets that are farmed,

\footnotetext{
260. Robinson, supra note 7, at 5.

261. Benoliel, supra note 79.

262. Bd. of Trade v. SEC, 677 F.2d 1137, 1162 (7th Cir. 1982) ("The word 'commodity' shall mean wheat, cotton, rice, corn, oats, barley, rye, flaxseed, grain sorghums, mill feeds, butter, eggs, Solanum tuberosum (Irish potatoes), wool, wool tops, fats and oils (including lard, tallow, cottonseed oil, peanut oil, soybean oil and all other fats and oils), cottonseed meal, cottonseed, peanuts, soybeans, soybean meal, livestock, livestock products, and frozen concentrated orange juice, and all other goods and articles, except onions as provided in section 13-1 of this title, and all services, rights, and interests in which contracts for future delivery are presently or in the future dealt in ...”).
} 
mined, or extracted such as wheat, alloys, or oil. swings. ${ }^{263}$ Commodities typically have a globally uniform price (ignoring currency inflation and transaction costs like shipping and taxes) that trade in high quantities in liquid markets, giving rise to price-hedging and speculation activities like option and futures contracts. ${ }^{264}$

Utility tokens, which act as the vital native cryptocurrency to their DAPPs ecosystem, are fungible and have a uniform global price. Additionally, tokens, when not sold in an ICO, are often "mined" assets that can be sold for fiat currency in highly liquid exchanges, and could be the subject of futures and options contracts. In sum, tokens seem to be a quintessential commodity. The purchase of commodities for personal consumption or commercial use is not a transaction in securities. ${ }^{265}$

Even if courts do not buy the argument that tokens are commodities, they should be viewed as assets that provide access to a good or service, like gift cards. It is not dispositive that token values are volatile. If someone buys a gift card to a new restaurant downtown, the conventional wisdom that ninety-plus percent of restaurants fail and the card may therefore lose its utility does not make the sale a security. ${ }^{266}$ We could draw a more cynical analogy and view buying tokens as a gamble: yet blackjack chips are little more than risk-laden gift cards to the table at a casino and therefore have personal consumptive value (like risky utility tokens).

\section{CONCLUSION}

The use of Initial Coin Offerings to sell crypto-assets for decentralized blockchain applications is a technological, financial, and legal Wild West. Amid an explosion of popularity for ICOs, novel regulatory challenges abound. Among them is whether and when ICOs constitute the sale of securities, namely investment contracts. This Comment endeavored to provide high-level background and analysis on that question which much

263. H.T., What Makes Something a Commodity?, THE ECONOMIST (Jan. 3, 2017), https://www.economist.com/blogs/economist-explains/2017/01/economist-explains-0 [https://perma. cc/BB25-GVTK].

264. Id.

265. Cf. Landreth Timber Co. v. Landreth, 471 U.S. 681, 689 (1985) (“Applying the Howey test, we concluded that the instruments likewise were not 'securities' by virtue of being 'investment contracts' because the economic realities of the transaction showed that the purchasers had parted with their money not for the purpose of reaping profits from the efforts of others, but for the purpose of purchasing a commodity for personal consumption.").

266. Note, however, this analysis may depend on how developed the blockchain application is. For analogy, if the gift cards are pre-sold to fund the building of the restaurant, they could be treated as securities, just like the pre-sold memberships of an unbuilt country club. See Silver Hills Country Club v. Sobieski, 361 P.2d 906, 908-09 (Cal. 1961). 
public debate is centered.

Although the SEC clearly intends to classify the majority of ICOs as the sale of securities under the Securities Act of 1933 and therefore require registration before sale, courts will in the near future have to decide whether they agree in principle, and in each specific instance in which litigation arises. In doing so, courts should exercise careful restraint and hold that ICOs of certain DAPP assets - utility tokens, specifically - can and sometimes should be viewed as the sale of a commodity or asset rather than an investment contract. In applying the seminal investment contract test, the Howey test, courts should recognize the economic realities surrounding this bleeding edge technology and far-reaching policy implications of such determinations. 